\title{
21. GEOMAGNETIC POLARITY TRANSITION RECORDS FROM FIVE HYDRAULIC PISTON CORE SITES IN THE NORTH ATLANTIC ${ }^{1}$
}

\author{
B. M. Clement and D. V. Kent, Lamont-Doherty Geological Observatory and Department of Geological Sciences, \\ Columbia University ${ }^{2}$
}

\begin{abstract}
Eleven geomagnetic polarity transition records from five hydraulic piston core sites in the North Atlantic are presented. The Matuyama-Brunhes reversal was sampled at five sites and the upper and lower Jaramillo and upper Olduvai transitions were each sampled at two sites. The wet sediment was sampled by taking U-channel samples across the reversals, as defined by conventional shipboard magnetostratigraphic studies. The U-channel samples were subsampled on shore by taking successive 0.5 - $\mathrm{cm}$-thick slices of the sediment.

The amount of detail contained in the records of these transitions is not always directly related to sedimentation rate. In seven out of eleven transitions, detailed sampling of cores deposited at moderate to high sedimentation rates $(30-50 \mathrm{~m} / \mathrm{m} . \mathrm{y}$.) failed to produce detailed transition records. The lack of intermediate directions demonstrated to be carried by single-component magnetizations indicates that these sections do not contain accurate records of transitional field behavior. The four transitions sampled from Hole 609B $(82.5 \mathrm{~m} / \mathrm{m} . \mathrm{y}$.$) , however, exhibit intermediate directions$ that are carried by univectorial magnetizations. A progression of directions through these reversals is also observed. These records therefore satisfy the basic criteria required to allow this interpretation in terms of geomagnetic field behavior.

Data from these mid-northern latitude transitions place additional constraints on existing transitional field models of the Matuyama-Brunhes reversal. The lower Jaramillo and upper Olduvai transitions obtained in this study are compared with records of these same reversals at a midsouthern latitude site. Comparison of these transitions reveals symmetries that are dependent upon the sense of the reversal with respect to the hemisphere on which the site is located. These symmetries are predicted by two different transitional field models in which an axisymmetric quadrupole term is dominant.
\end{abstract}

\section{INTRODUCTION}

Pelagic sediments are characterized by relatively constant accumulation rates. This suggests that conventional piston cores of such sediment should provide polarity transition records with the geographic distribution required to test transitional field models adequately. Recent results, however, indicate that cores deposited at slow sedimentation rates do not always provide improved resolution of the transitions with more detailed sampling. It appears that a level of sampling is reached beyond which inhomogeneities in the magnetizations exist on the scale of the sample's size (Clement and Kent, 1984a). Cores deposited at higher sedimentation rates are less affected by this problem and can give very detailed transition records (Clement and Kent, 1984b). Unfortunately, high sedimentation rate records are rare because piston cores are limited to 20 to $30 \mathrm{~m}$ in length. Unless a hiatus is encountered between the top of the core and the reversal, the Matuyama-Brunhes reversal is out of reach if rates are much greater than $30 \mathrm{~m} / \mathrm{m} . \mathrm{y}$.

The development of the hydraulic piston corer (HPC) and its use on Deep Sea Drilling Project (DSDP) legs has led to the recovery of very long sections of undisturbed sediment, suitable for paleomagnetic study (Kent

\footnotetext{
${ }^{1}$ Ruddiman, W. F., Kidd, R., Thomas, E., et al,, Init. Repts. DSDP, 94: Washington (U.S. Govt. Printing Office).

2 Address: (Clement, present address) Ocean Drilling Program and Department of Geophysics, Texas A\&M University, College Station, TX 77843; (Kent) Lamont-Doherty Geological observatory and Department of Geological Sciences, Columbia University, Palisades, NY 10964.
}

and Spariosu, 1982; Tauxe, Tucker, et al., 1983). The ability to recover such thick sequences greatly improves the chances of obtaining records of polarity transitions in sediments accumulated at high sedimentation rates. During DSDP Leg 94 six sites were drilled in the North Atlantic, a basin characterized by higher than average pelagic sedimentation rates. On the basis of shipboard magnetostratigraphy, eleven reversal boundaries were selected for detailed shore-based study.

\section{METHODS}

The magnetostratigraphy of the 21 holes cored during DSDP Leg 94 is discussed in detail in Clement and Robinson (this volume). With the hydraulic piston corer (HPC), undisturbed sections were recovered, characterized by high sedimentation rates at each of these sites $(30-80 \mathrm{~m} / \mathrm{m}$.y.). The primary objective of Leg 94 was to obtain a transect in the North Atlantic (from $37-53^{\circ} \mathrm{N}$ ) of complete paleoclimatic records extending back to $3 \mathrm{Ma}$ (see Introduction and Explanatory Notes chapter, this volume). Therefore at each site multiple holes were cored to minimize the length of record lost to coring disturbances at core breaks. Sampling of polarity transitions was limited to the secondary hole at each site because of the shipboard sampling volume in the first hole.

Although long, high sedimentation rate sequences were obtained on this leg, only polarity transitions younger than the Gauss Chron were sampled because of the low magnetization intensities observed from the base of the Matuyama through the Gilbert chronozones at most sites. The intensities increased below the Gilbert, but we concentrated on obtaining the younger records for which transitions from other sites already were documented. The sampling was limited to transitions that occurred within single core sections, avoiding the disturbances commonly observed near the tops of cores and less frequently at core section boundaries. The sampled polarity transitions are listed in Table 1, which provides the location, the sub-bottom depth of the reversal, the interval sampled, and the sedimentation rates for the sampled transitions as well. 
Table 1. Polarity transitions.

\begin{tabular}{|c|c|c|c|c|c|c|c|}
\hline \multirow[b]{2}{*}{ Hole } & \multicolumn{2}{|c|}{ Position } & \multirow[b]{2}{*}{ Reversal boundary } & \multirow{2}{*}{$\begin{array}{l}\text { U-channel interval } \\
\text { (core-section, } \\
\text { interval in cm) }\end{array}$} & \multirow{2}{*}{$\begin{array}{l}\text { Sub-bottom } \\
\text { depth (m) }\end{array}$} & \multicolumn{2}{|c|}{$\begin{array}{l}\text { Sedimentation } \\
\text { rate }(\mathrm{m} / \mathrm{m} . \mathrm{y} .)\end{array}$} \\
\hline & Lat. $\left({ }^{\circ} \mathrm{N}\right)$ & Long. $\left({ }^{\circ} \mathrm{E}\right)$ & & & & Brunhes & Matuyama \\
\hline $606 \mathrm{~A}$ & 37.33 & 324.5 & Matuyama-Brunhes & $3-4,0-55$ & $19.70-20.25$ & 27.6 & 34.37 \\
\hline \multirow[t]{4}{*}{$607 \mathrm{~A}$} & 41.0 & 327.05 & Matuyama-Brunhes & $5-5,0-26$ & $36.48-36.74$ & 49.79 & 42.65 \\
\hline & & & upper Jaramillo & $6-3,45-97$ & $43.56-44.08$ & - & 42.65 \\
\hline & & & lower Jaramillo & $6-6,0-40$ & $47.56-47.96$ & - & 42.65 \\
\hline & & & upper Olduvai & $9-5,99-145$ & $75.88-76.36$ & - & 42.65 \\
\hline \multirow[t]{4}{*}{ 609B } & 49.86 & 335.77 & Matuyama-Brunhes & $6-1,41-98$ & $42.41-42.99$ & 58.47 & 82.5 \\
\hline & & & upper Jaramillo & $7-4,10-114$ & $56.21-57.25$ & - & 82.5 \\
\hline & & & lower Jaramillo & $8-2,26-124$ & $62.97-63.93$ & - & 82.5 \\
\hline & & & upper Olduvali & $14-1,49-150$ & $119.28-120.27$ & - & 82.5 \\
\hline $610 \mathrm{~B}$ & 53.21 & 341.12 & Matuyama-Brunhes & $6-1,98-148$ & $44.18-44.68$ & 60.86 & 56.8 \\
\hline $610 \mathrm{C}$ & 53.21 & 341.12 & Matuyama-Brunhes & $4-4,33-101$ & $40.42-41.13$ & 55.79 & - \\
\hline
\end{tabular}

Note: - indicates not applicable for this interval.

The shipboard paleomagnetic measurements used to determine the magnetostratigraphy on Leg 94 were made on $7-\mathrm{cm}^{3}$ samples taken at $1.5-\mathrm{m}$ intervals (nominally one per core section). Treatment at $10-\mathrm{mT}$ peak alternating field (AF) was found adequate to remove less stable components of magnetization and to isolate effectively the stable characteristic remanence (ChRM) of the samples (Clement and Robinson, this volume). The polarity transitions were identified by a nearly $180^{\circ}$ directional change observed in the record of the $7-\mathrm{cm}^{3}$ samples. Transitions to be sampled were further constrained by taking additional samples, until the depth interval recording the reversal was limited to approximately $50 \mathrm{~cm}$. A continuous sample was then taken of the sediment between the two samples limiting the transition using a "U-channel" plastic sample container as described by Tauxe, La Brecque, et al. (1983) (these sample containers measure $2.5 \mathrm{~cm} \times 2.5 \mathrm{~cm}$ in cross section and were cut to the required length).

The U-channel samples were subsampled and measured at the Lamont-Doherty paleomagnetics laboratory. A fine-gauge, stainless steel wire held in a coping saw frame was used to cut $0.5-\mathrm{cm}$ slices of sediment from the U-channel sections. These slices were oriented in plastic boxes and measured using a cryogenic magnetometer. Although shipboard results indicated that partial AF demagnetization at $10-\mathrm{mT}$ peak field was sufficient to clean the $7-\mathrm{cm}^{3}$ samples taken in full polarity zones, more detailed progressive AF demagnetization studies were carried out on transitional specimens. Every specimen from each U-channel was demagnetized at a minimum of three levels, with selected specimens subjected to progressive AF demagnetization at increments of $2.5 \mathrm{mT}$ to $5 \mathrm{mT}$, up to $30 \mathrm{mT}$ to $80 \mathrm{mT}$.

\section{RESULTS}

Of the eleven transitions sampled from Leg 94 sediments, only the four records from Hole 609B meet the basic criteria for acceptance as reliable paleomagnetic records across transition zones. The other seven records lack intermediate directions that can be demonstrated to be carried by single-component magnetizations; these seven transitions exhibit behavior very similar to that seen previously in conventional piston cores (Clement and Kent, 1984b), although the sedimentation rates were considerably higher at Leg 94 sites. The transition zones in these cores are possibly the products of a remanence-acquisition process in which the record of field behavior is complicated by sedimentological effects. These records cannot be readily interpreted in terms of transitional field behavior, but they are of interest in bringing into focus the problem of remanence acquisition in pelagic sediments. Results from these records are placed in category one and are presented first. The four records of the Matuyama-Brunhes are followed by the three older records from Hole 607A (the upper and lower Jaramillo and the upper Olduvai). The four records from Hole 609B are placed in category 2 and are presented last.

The results of progressive AF demagnetization studies of the transition zones are presented as vector endpoint diagrams (Zijderveld, 1967). The records (after treatment at the appropriate peak field level) are given as inclination, declination, and natural remanent magnetization intensity plotted versus depth. Because the cores were not oriented, the declinations are plotted relative to the split face of the core and not relative to geographic north. The intensities, unless otherwise stated, have not been normalized, but in most cases the specimens are of uniform volume $(0.5 \mathrm{~cm} \times 2.5 \mathrm{~cm} \times 2.5 \mathrm{~cm})$, and the relative changes downcore are not a product of variations in sample size. The data are plotted versus depth as measured from the top of a standard DSDP $1.5-\mathrm{m}$ core section. The sub-bottom depths are given in Table 1 for each U-channel sample.

The records from Hole 609B were examined further to obtain information about field behavior. In order to allow comparison of the directional records with results from other sites, virtual geomagnetic pole (VGP) paths are presented for each of these records. Because the cores were not oriented, the declination records were uniformly reoriented so that the full polarity mean values reached a meridional best fit, with normal polarity values equal to $0^{\circ}$ and the reverse values equal to $180^{\circ}$. The observation of inclinations that agree with values predicted by an axial dipole field (ADF) provides the justification for these adjustments.

Variation in the observed natural remanent magnetization (NRM) intensity records may be a function of geomagnetic field intensity variations (Irving and Major, 1964; Kent, 1973), downcore changes in the composition of the magnetic carrier or in the amount of carrier, or some combination of these factors (Verosub and Bannerjee, 1977). In an effort to isolate the effects of changes in the magnetic carrier the specimens from the sampled intervals were given anhysteretic remanent magnetization (ARM).

Normalization of the NRM record by the ARM record has been suggested as a method for determining relative paleointensities from sediments (Bannerjee et al., 1981). The ARM record may also be subject to such variables as grain size (King et al., 1982), and therefore it 
may not completely normalize for lithologic variations. If no variations are observed in the ARM record it is reasonable to examine the NRM variations in terms of a record of relative field behavior. But because relating the ARM acquisition process to the postdepositional remanent magnetization ( $\mathrm{pDRM}$ ) process is not straightforward, analyzing the meaning of ARM variations and how these correlate to changes in the NRM record is difficult.

\section{Category 1}

\section{Matuyama-Brunhes Transitions}

\section{Hole 606 A}

Results of progressive AF demagnetization from three reversely magnetized specimens from the MatuyamaBrunhes transition in Hole 606A are presented in Figure 1. Note that the magnitude of the ChRM decreases approaching the reversal, whereas the magnitude of the downwardly directed, low-coercivity component remains approximately the same. Hence, the overprint becomes a larger proportion of the total NRM as the ChRM decreases, making precise determination of the ChRM more difficult. This behavior is observed frequently in the lower sedimentation rate transitions sampled on this leg. The origin of the low-coercivity component remains unclear. It is too steep to be interpreted as an in situ normal polarity overprint and may be a product of the coring process or acquired in the laboratory-the two instances in which the specimens were exposed to a steep downward ambient field.

The results obtained from the Matuyama-Brunhes transition after partial $\mathrm{AF}$ demagnetization at $15 \mathrm{mT}$ are presented in Figure 2. The sample thickness was initially increased to $1.0 \mathrm{~cm}$ because of the relatively low intensi- ties observed across this interval, but was decreased to $0.5 \mathrm{~cm}$ after results proved the thinner specimens to be readily measurable. The Matuyama-Brunhes reversal is identified by a nearly $180^{\circ}$ directional change from directions in excellent agreement with those predicted by a reversed to normal axial dipole field $\left(+56.7^{\circ}\right.$ ) (reverse mean: $\mathrm{n}=10$, depth interval $=43-52 \mathrm{~cm}$, decl. $=$ $289.1^{\circ}$, incl. $=-59.1^{\circ}, \mathrm{k}=260.1$, alpha $95=2.7^{\circ}$; normal mean: $\mathrm{n}=10$ for depths $1.0-6.0 \mathrm{~cm}$, decl. = $91.3^{\circ}$, incl. $=57.6^{\circ}, \mathrm{k}=106.3$, alpha $95=4.3^{\circ}$ ) (Fisher, 1953).

The transition from reverse to normal polarity is not recorded as a smooth progression in the directional data. In particular, the declination record is marked by considerably more scatter than is present above and below the transition. The boundaries of the transition zones are defined as the depths at which the directions begin to exceed systematically the circular standard deviation (CSD) of the full polarity means (see Clement and Kent, 1984b). This definition is used to determine the thicknesses of the transition zones. In this case, intermediate directions are observed across $12 \mathrm{~cm}$ of section (13.0$25.0 \mathrm{~cm}$ ). The intensity record exhibits a low, in which values drop by one order of magnitude, centered on the directional change. Another low occurs below $50 \mathrm{~cm}$, in the fully reversed polarity zone, indicating that the low observed at the level of the directional change may not be outside the range of full polarity intensity fluctuations as recorded at this site.

\section{Hole 607A}

From this transition, obtained after AF treatment at $10 \mathrm{mT}$, almost no intermediate directions were observed even on the scale of $0.5 \mathrm{~cm}$. Additional problems included the considerable amount of scatter observed in the full polarity zones. The NRM record revealed a gradual

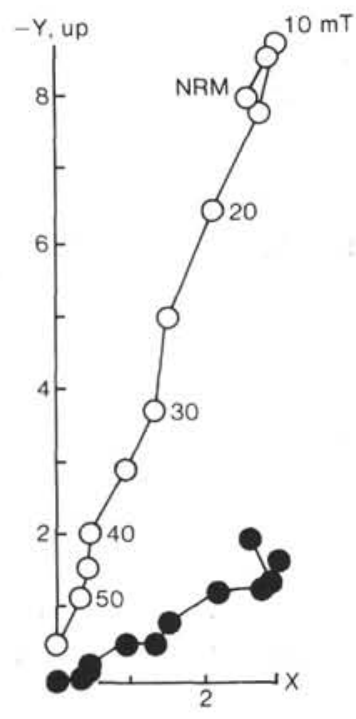

$35 \mathrm{~cm}$

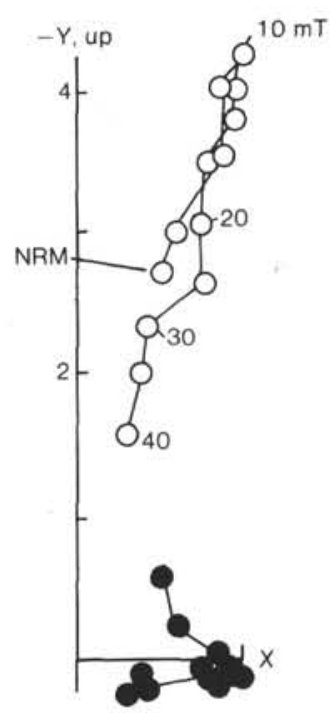

$25.5 \mathrm{~cm}$

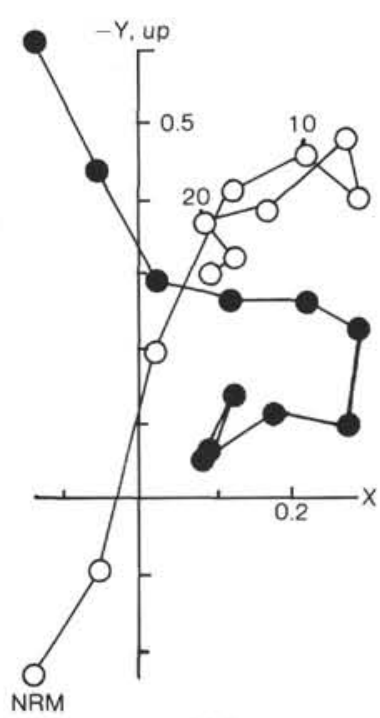

$20.5 \mathrm{~cm}$

Figure 1. Results of progressive AF demagnetization of specimens from the Matuyama-Brunhes transition at Hole $606 \mathrm{~A}$ plotted as vector endpoint diagrams. Solid symbols represent projection onto the horizontal plane, open symbols projection onto the vertical plane. Plotted in units of $1 \times 10^{-3} \mathrm{~A} / \mathrm{m}$. 


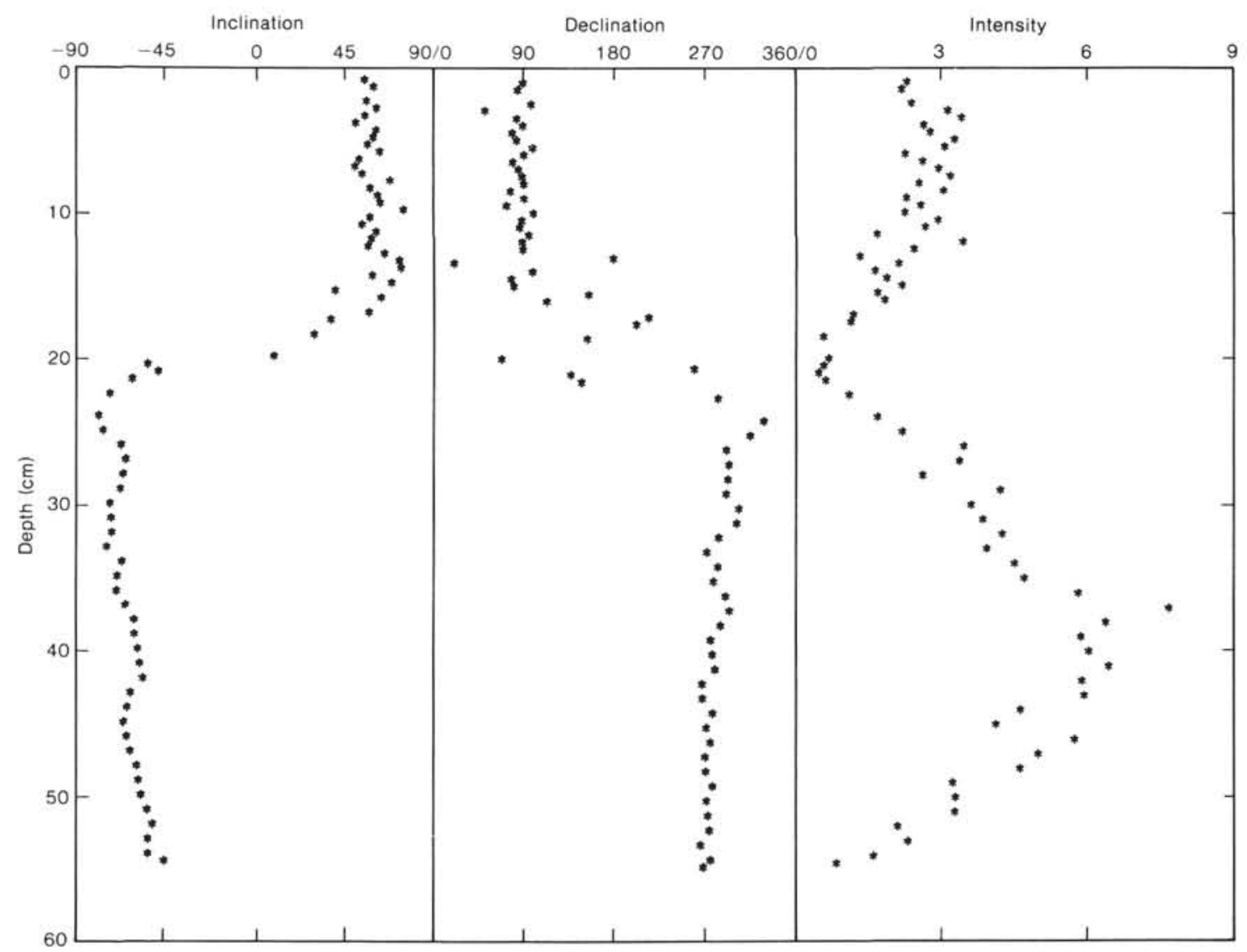

Figure 2. Inclination and declination $\left({ }^{\circ}\right)$, and NRM intensity records after AF treatment at $15 \mathrm{mT}$ of the Matuyama-Brunhes transition from Hole $606 \mathrm{~A}$ plotted versus depth in section. (Intensities are plotted in units of $1 \times 10^{-3} \mathrm{~A} / \mathrm{m}$ ).

progression in inclination and declination from reverse polarity directions below $24 \mathrm{~cm}$ to normal polarity directions above $10 \mathrm{~cm}$. Each specimen from this section was measured after AF demagnetization at $1-\mathrm{mT}$ increments from 5 to $10 \mathrm{mT}$ and then at $5-\mathrm{mT}$ increments up to at least $35 \mathrm{mT}$. Results of this treatment reveal the presence of a strong, downwardly directed overprint in each of these specimens that appeared to be removed after treatment at $10 \mathrm{mT}$.

The Matuyama-Brunhes transition record obtained after treatment at $10 \mathrm{mT}$ is plotted in Figure 3. Although the demagnetization studies appeared to be successful in removing the steep downward component, the inclination record exhibits normal polarity values that are too steep, and reversed polarity values that are too shallow, suggesting that the downward component has not been thoroughly removed. This behavior prompted the demagnetization to higher peak fields, which proved unsuccessful in isolating the predicted full polarity values more accurately.

The intensity record exhibits a steady decline from a depth of 25.5 to $9.5 \mathrm{~cm}$ and then abruptly increases at $9.0 \mathrm{~cm}$ to values that remain constant to the top of the sampled interval. This abrupt increase does not occur at the same depth as the directional change $(11 \mathrm{~cm})$.

\section{Site 610}

Six holes were cored at Site 610 on the Feni sediment drift. Four of these holes, including Holes $610 \mathrm{~B}$ as well as $610 \mathrm{C}$, were cored on the crest of a sediment wave. U-channel samples were taken across the MatuyamaBrunhes reversal as determined by the shipboard paleomagnetic measurements in Holes 610B and 610C in an effort to compare transition records obtained from holes at a minimal distance. A 70-cm-long U-channel was taken across the reversal in Hole $610 \mathrm{C}$ and will be discussed first, and a 50-cm-long sample was taken across the reversal in Hole 610B.

The record from Hole 610C (after AF treatment at $25 \mathrm{mT}$ ) is presented in Figure 4. A full $180^{\circ}$ directional change is not observed within the U-channel sample. The directions at the ends of the sample agree with the discrete sample record at either end, giving directions of: decl. $=231.3^{\circ}$, incl. $=69 \cdot 2^{\circ}$ and decl. $=67 \cdot 1^{\circ}$, incl. $=-69 \cdot 3^{\circ}$. One meter and a half below the base of the U-channel sample a direction of decl. $=56.8^{\circ}$, incl. $=$ $74.5^{\circ}$ was observed. Thus it appears that the full directional change occurs over a longer interval than was sampled by the U-channel. If this is the case, this record is intriguing in that most of the inclination change occurs across a short interval $(20 \mathrm{~cm})$ relative to the declination change $(>70 \mathrm{~cm})$, although a trend in the inclination record (values steepening upcore from -67.8 to $-75^{\circ}$ ) exists from 100 to $70 \mathrm{~cm}$. From 70 to $58 \mathrm{~cm}$, the between-specimen scatter increases and the greatest inclination change occurs. The intensity record from Hole 610C exhibits a broad low from 90 to $50 \mathrm{~cm}$; trends at the upper and lower ends of the section indicate that the 


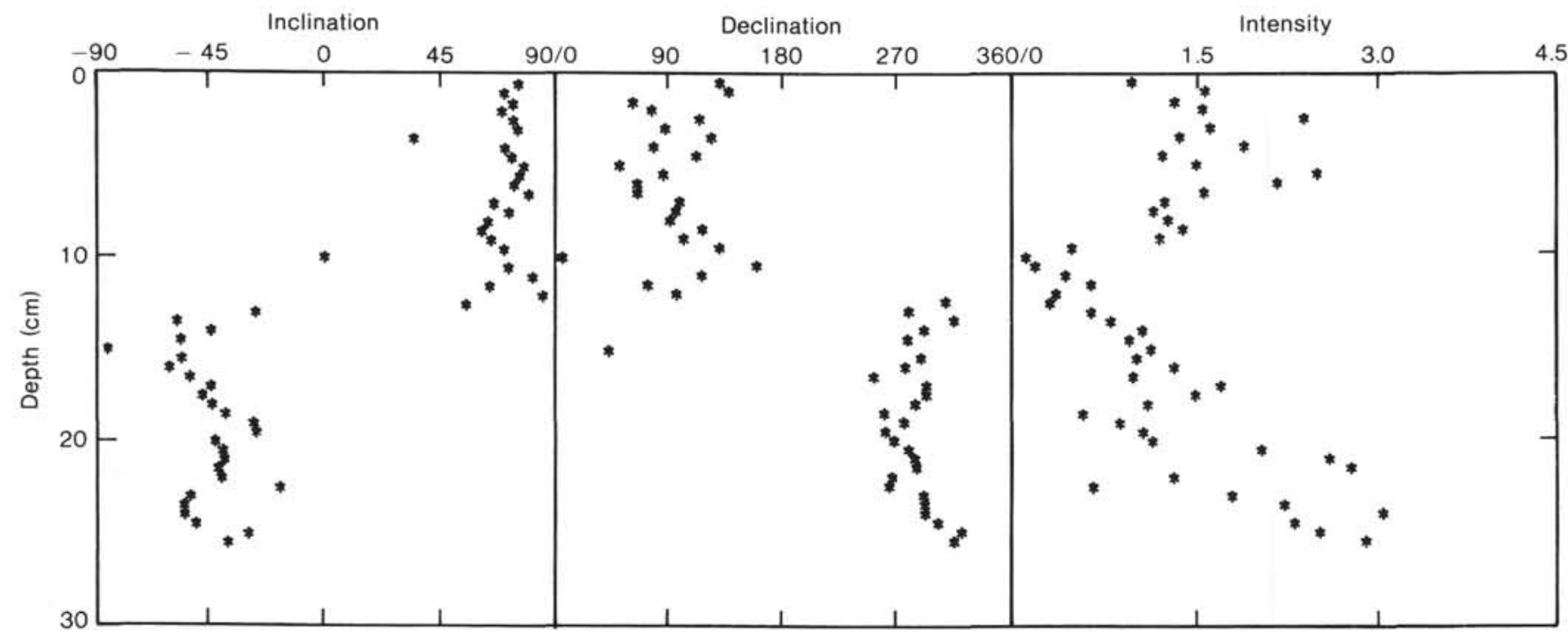

Figure 3. Inclination and declination $\left({ }^{\circ}\right)$, and NRM intensity records of the Matuyama-Brunhes transition obtained from Hole 607A plotted versus depth in section after AF demagnetization at $10 \mathrm{mT}$. Intensities are plotted in units of $1 \times 10^{-3} \mathrm{~A} / \mathrm{m}$.

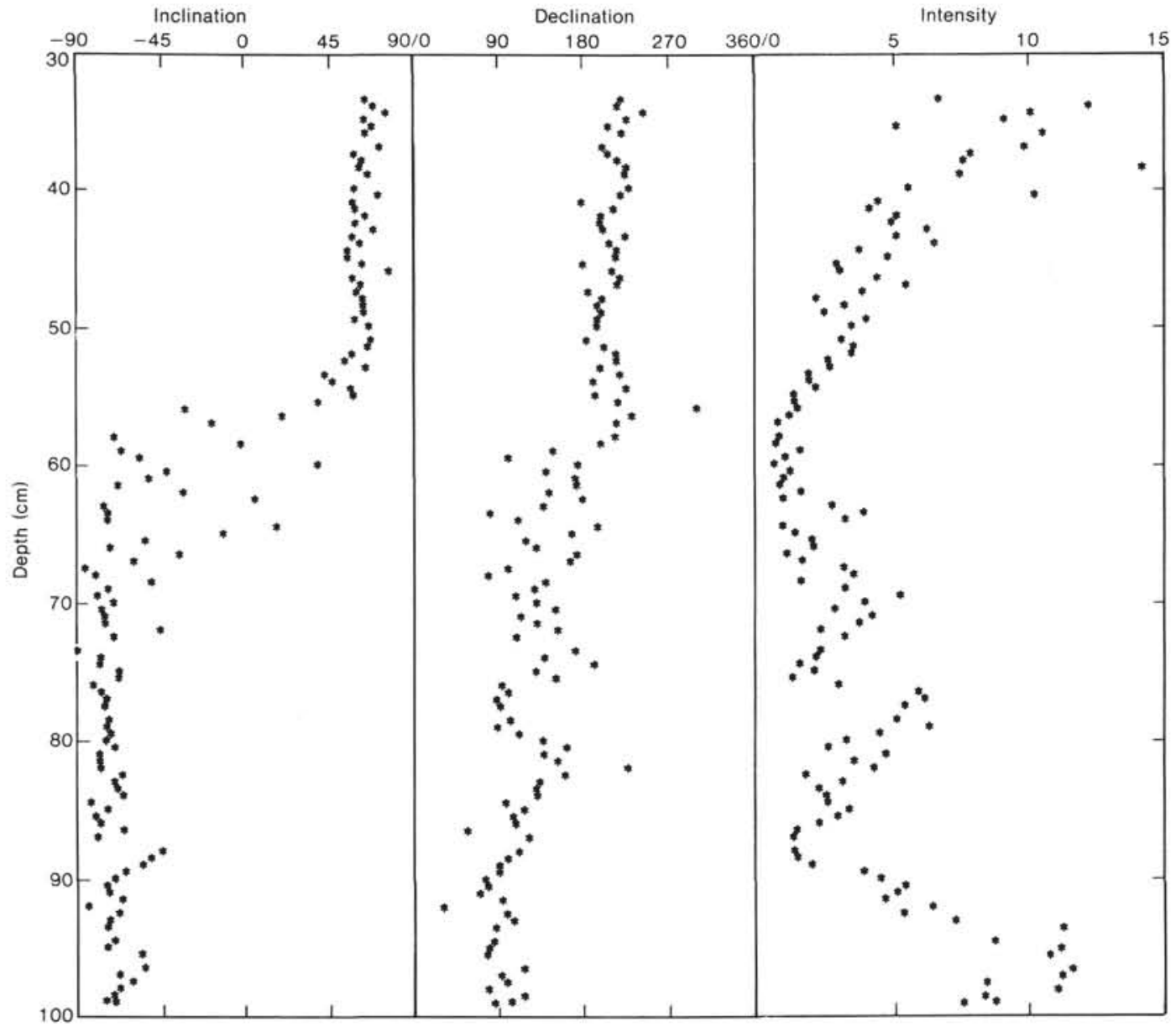

Figure 4. The results obtained after $\mathrm{AF}$ demagnetization at $25 \mathrm{mT}$ from the Matuyama-Brunhes polarity transition obtained from Hole $610 \mathrm{C}$ plotted versus depth in section. Intensities are plotted in units of $1 \times 10^{-3} \mathrm{~A} / \mathrm{m}$. 
intensities may continue to change in both directions. Because of the suspected incomplete nature of this record, it is not examined in detail, although portions of it may represent records of transitional field behavior.

The problems in the Matuyama-Brunhes transition record in Hole $610 \mathrm{C}$ were not clarified by the record of the same reversal obtained from Hole 610B (Fig. 5). In this record the mean inclinations above and below the reversal are too steep ( 75.8 and $-80.7^{\circ}$, respectively). The declination record is marked by a large amount of scatter above and below the reversal. Results from the discrete samples above and below this interval defined a more complete reversal, with the sample immediately above yielding a direction of decl. $=266^{\circ}$, incl. $=$ $81.6^{\circ}$, whereas $1 \mathrm{~m}$ below the base of the U-channel sample, directions of decl. $=93.7^{\circ}$ and incl. $=78.6^{\circ}$ were obtained. The data from the discrete samples show anomalously steep inclinations, although the declinations show a nearly complete reversal $\left(172^{\circ}\right)$. The intensity record from Hole 610B shows a decrease in values from the top of the section to $40 \mathrm{~cm}$, below which the values increase along with an increase in scatter.

Comparison of these two records (Holes 610B and $610 \mathrm{C}$ ) reveals similarities in the intensity records and in the relative timing of the inclination reversal with respect to the intensity record. In both cases the inclination change coincides with the depth above which the intensities begin to increase upcore. Unfortunately, the large amount of scatter, especially in the Hole $610 \mathrm{~B}$ record, makes comparison of these records on a finer scale difficult. The data from the discrete samples indicate that the U-channel samples may span only a portion of the total directional change. Because of the large amount of between-specimen scatter in these sections, however, sampling was not extended up- and downcore as appears to be required to sample the entire transition.

\section{Hole 607A}

\section{Upper Jaramillo}

The results from the upper Jaramillo transition from Hole 607A are presented in Figure 6. From 95 to $65 \mathrm{~cm}$ the inclinations are in close agreement with those predicted by a reversed axial dipole field (ADF) of $-60^{\circ}$ for this latitude. The declination record exhibits good serial correlation across this interval. Above $65 \mathrm{~cm}$, however, the NRM intensities become so weak that the increased scatter is attributed to instrumental noise. The discrete sample record indicates that the upper Jaramillo reversal occurs across the interval sampled by the U-channel. Partial AF demagnetization of the basal U-channel specimens to higher peak fields indicates that a steep downward component had not been removed in the discrete sample from near this depth: the reversal apparently occurs further downcore. Because of the extremely low NRM intensities across this interval, the record was not extended farther downcore even though a full reversal was not observed within the sampled interval.

\section{Lower Jaramillo and Upper Olduvai}

The results from the lower Jaramillo reversal from Hole 607A prior to demagnetization are plotted in Figure 7. The full reversal was not observed in the NRM data, although the discrete samples next to the U-chan-

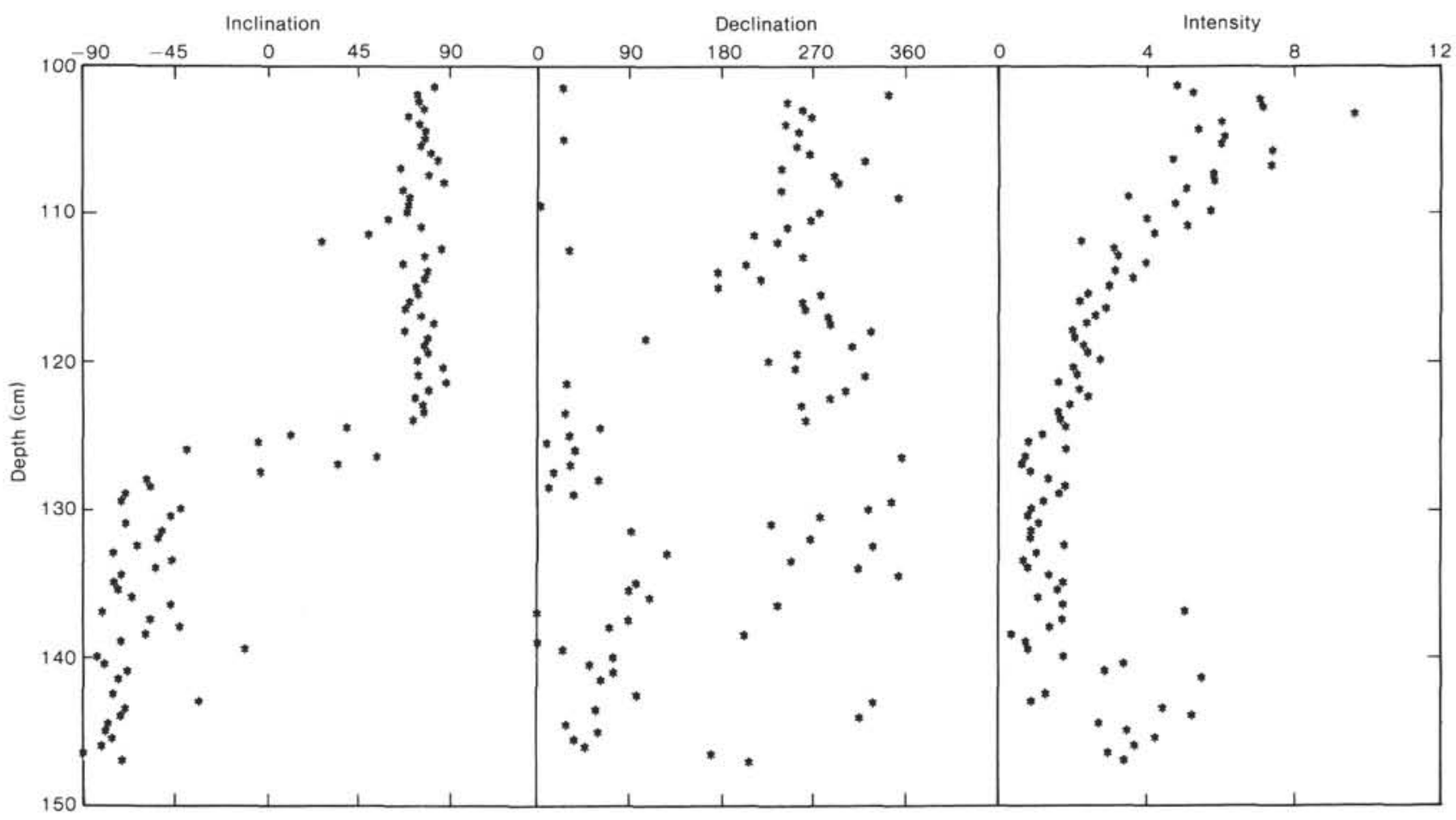

Figure 5. The results from the Matuyama-Brunhes polarity transition from Hole 610B after AF demagnetization at $25 \mathrm{mT}$ plotted as depth in section. The intensities are plotted in units of $1 \times 10^{-3} \mathrm{~A} / \mathrm{m}$. 


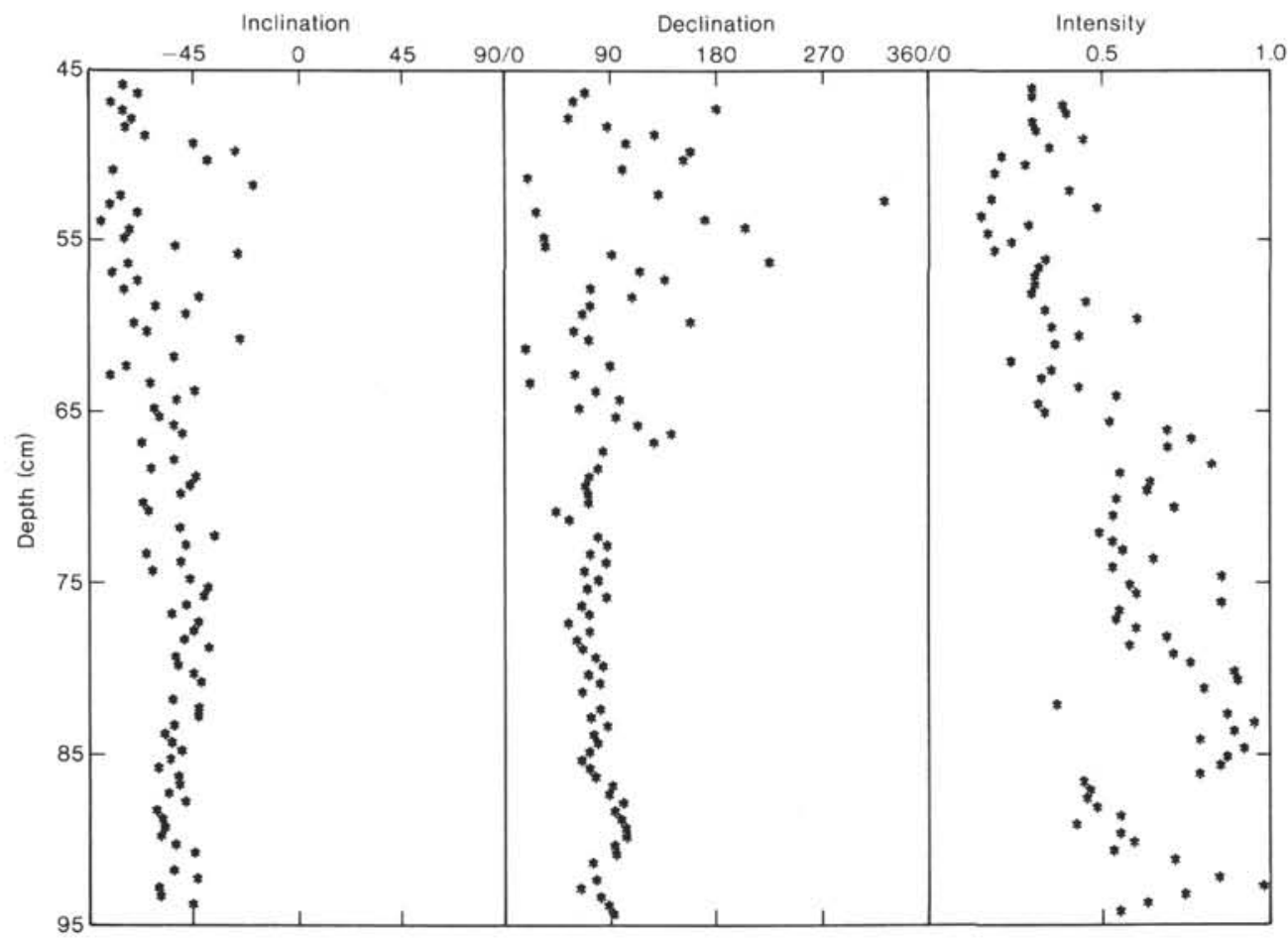

Figure 6. Results of the upper Jaramillo transition from Hole 607A plotted versus depth in section after treatment at $15 \mathrm{mT}$. The intensities are plotted in units of $1 \times 10^{-3} \mathrm{~A} / \mathrm{m}$.

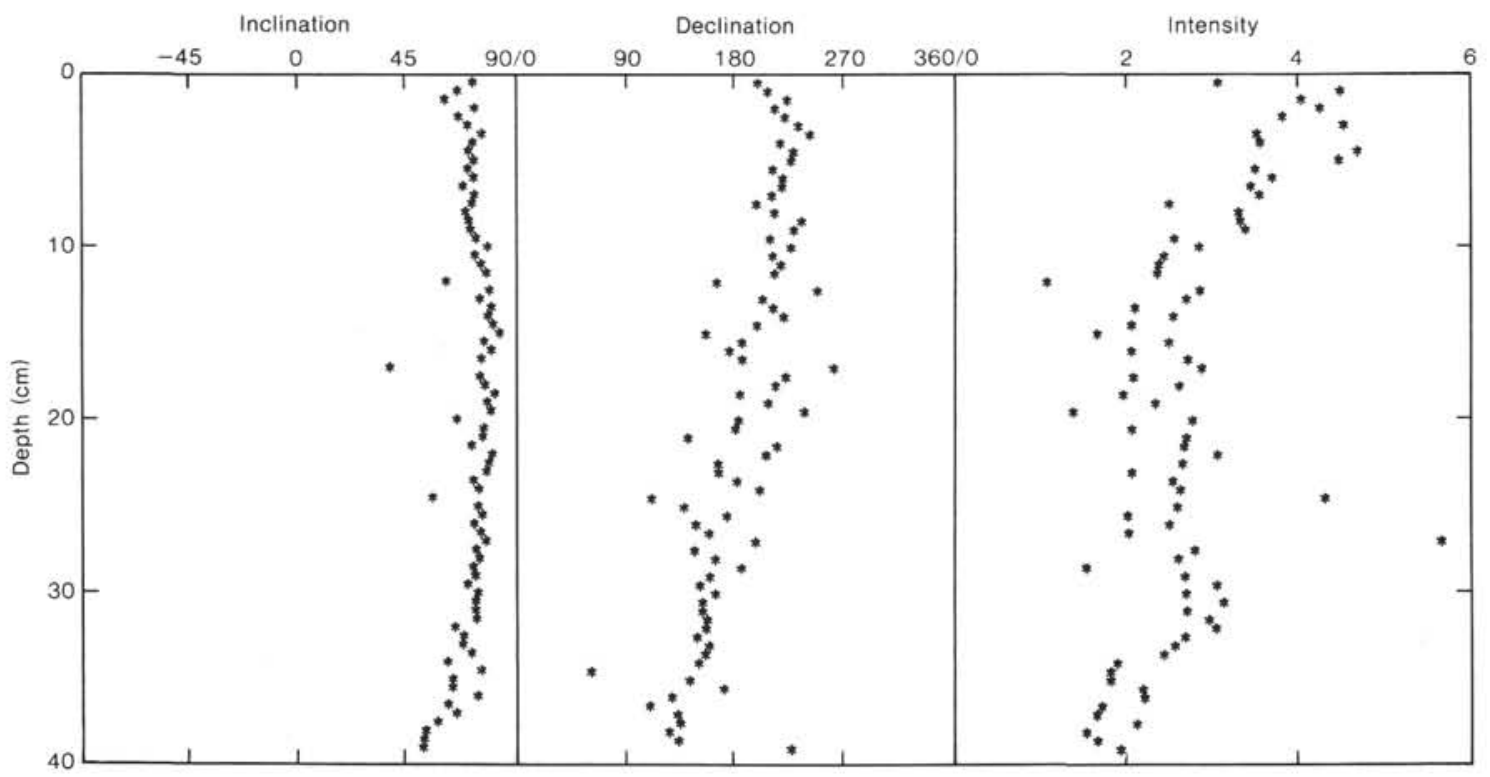

Figure 7. Results from the lower Jaramillo transition from Hole 607A prior to AF treatment plotted versus depth in section. Intensities are in units of $1 \times 10^{-3} \mathrm{~A} / \mathrm{m}$.

nel sample revealed a nearly $180^{\circ}$ directional change after treatment at $10 \mathrm{mT}$. Results of progressive AF demagnetization indicate that specimens from the top of the U-channel sample reveal well-defined trajectories decaying toward the origin with further treatment at higher fields, but specimens from the base of this U-channel sample exhibit trajectories that bypass the origin. Treatment at 30 to $40 \mathrm{mT}$ failed to define a component that decayed to the origin, and further demagnetization was not possible because the intensities were approaching the instrumental noise level at these fields. Similar behavior was observed from the upper Olduvai reversal at this site. The NRM results from the upper Olduvai at this site are shown in Figure 8.

In order to observe the behavior of these specimens after treatment at higher demagnetization fields, a stacking method was developed in which composite samples were created by stacking three stratigraphically adjacent 


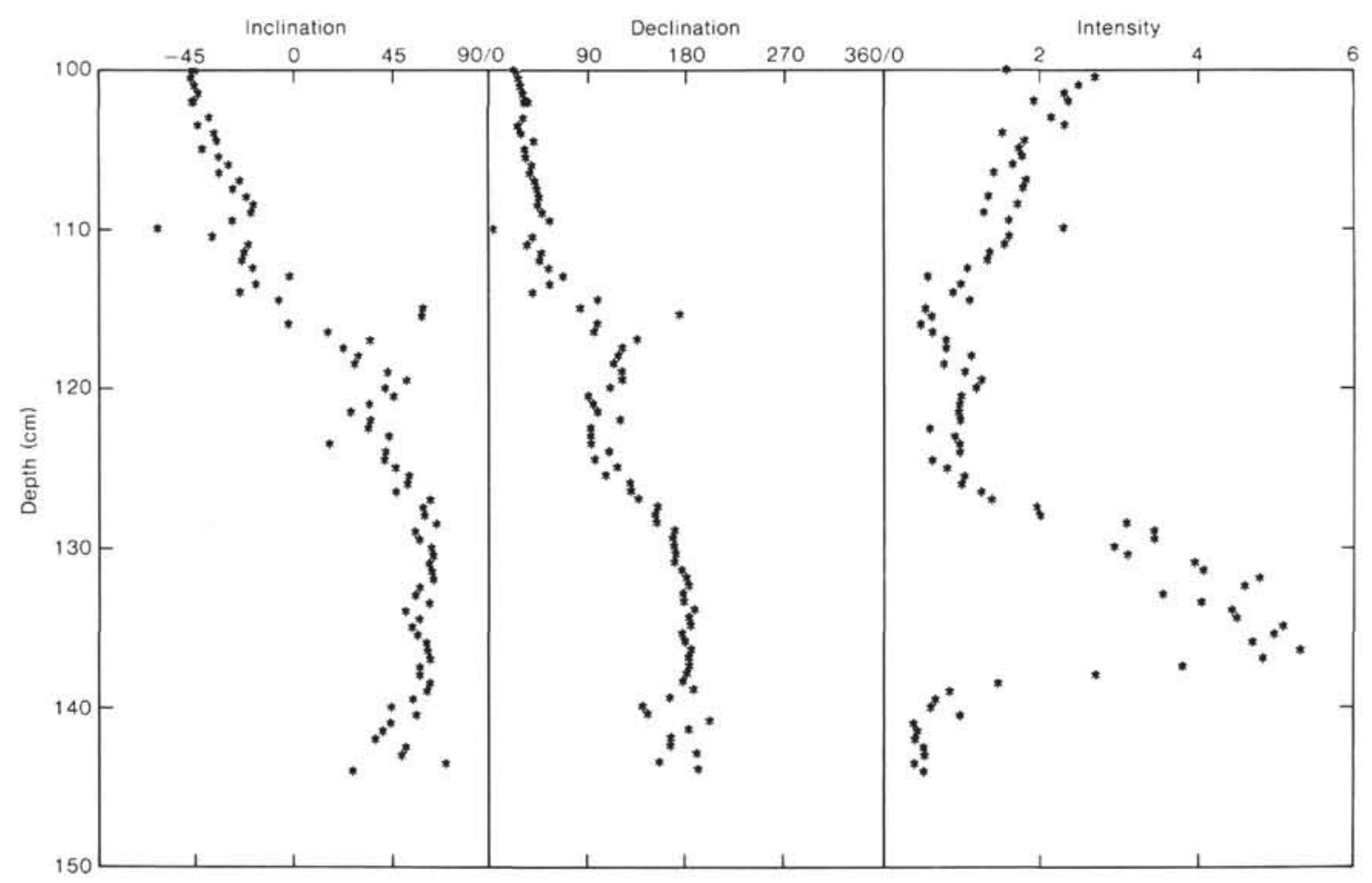

Figure 8. The upper Olduvai transition NRM record obtained from Hole 607A, plotted as depth in section. Intensities are plotted in units of $1 \times 10^{-3} \mathrm{~A} / \mathrm{m}$.

specimens together in one plastic box. This increased the volume of the sample, increasing the total moment, thereby increasing the signal-to-noise ratio. This allowed measurement after treatment at higher peak AF fields. After measurement, the top specimen was removed and the next, stratigraphically lower specimen was added to the bottom of the stack, and the demagnetization treatment and measurement were repeated. This process was repeated throughout the sampled interval and the entire sequence was repeated at each successively higher peak field level. In this way a physical running mean was obtained at each treatment level. AF curves for each stacked sample were also obtained, with every specimen contributing to each of three successively stacked samples.

Examples of the results of this process are shown as vector endpoint diagrams in Figure 9. It is clear from Figure 9A and 9B that treatment at higher levels allows the definition of multiple components. In particular, three distinct components are defined in the two samples shown in Figure 9C and 9D. These multicomponent magnetizations remain problematical, however, because even after treatment at 40 to $50 \mathrm{mT}$ a component decaying toward the origin had not been isolated. The steep downward-directed component carried in the low-coercivity range is similar to that seen in the sites previously discussed. The steep upward directions carried in the 25 to $50 \mathrm{mT}$ coercivity range cluster about the reversed polarity mean direction (in this normal to reverse transition, these upward directions parallel the subsequent polarity direction), whereas the intermediate coercivity range appears to yield directions that are consistently more shallow than the other two components. Unfortunately a consistent progression of this component is not observed through this section, and a convincing argument that the intermediate component is recording transitional field behavior cannot be made.

\section{Category 2}

\section{Hole 609B}

The results from the Matuyama-Brunhes, upper Jaramillo, lower Jaramillo, and upper Olduvai polarity transitions obtained from Hole 609B are presented below. The Hole 609B specimens exhibit straightforward behavior during progressive $\mathrm{AF}$ demagnetization (unlike the data discussed above from Holes 606A, 607A, 610B, and $610 \mathrm{C}$ ), and even the lowest NRM intensity values were well above the instrumental noise level. These records also exhibit internal consistency as evidenced by good serial correlation through the transition zones. Therefore the transition records are more readily interpreted as containing information regarding the behavior of the geomagnetic field during a polarity transition.

Selected specimens from the transition records from Hole 609B were subjected to ARM acquisition experiments using a $0.05 \mathrm{mT}$ dc field coaxial with an ac field that was incrementally increased. Results are shown in Figure 10, from which it can be seen that saturation is approached by $100 \mathrm{mT}$. Based on these results the specimens from the U-channel samples were given ARMs using a $0.05-\mathrm{mT}$ dc field coaxial with a $120-\mathrm{mT}$ ac field.

\section{Matuyama-Brunhes}

Progressive AF demagnetization of specimens from the U-channel sample spanning the Matuyama-Brunhes 
A

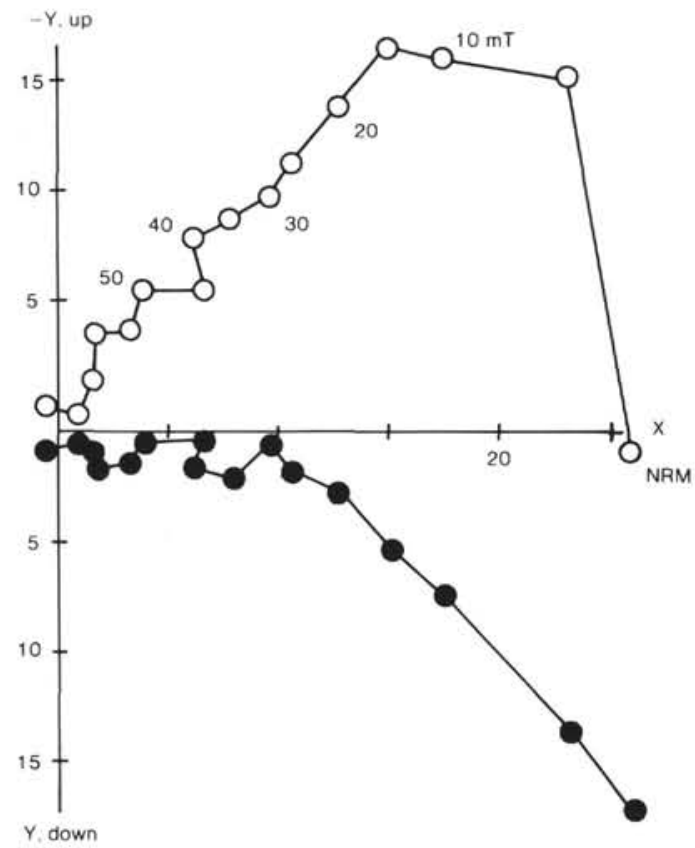

C

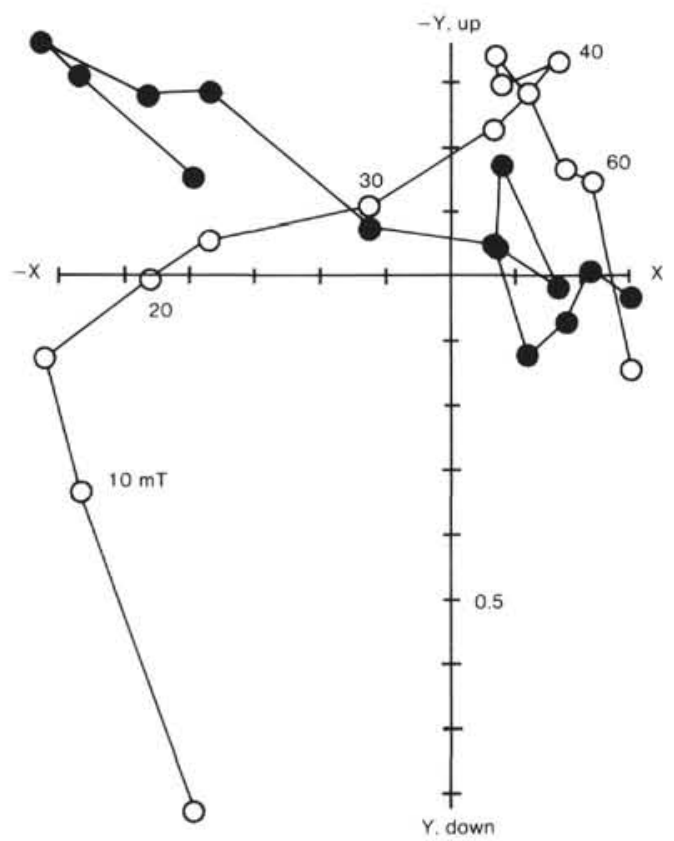

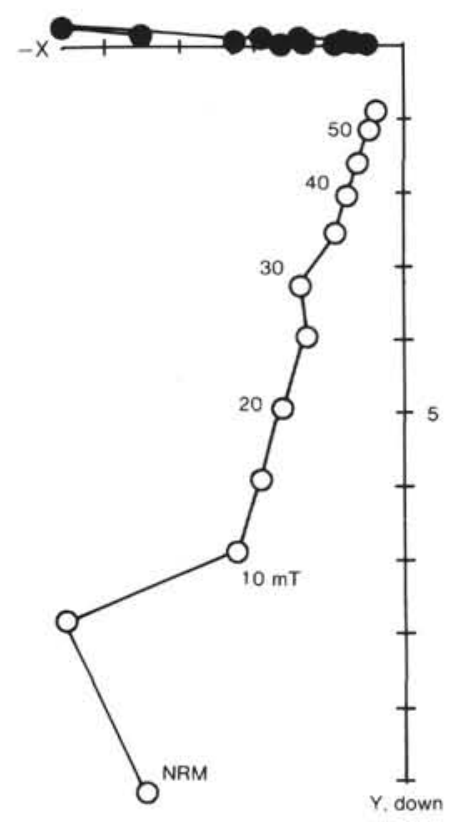

D

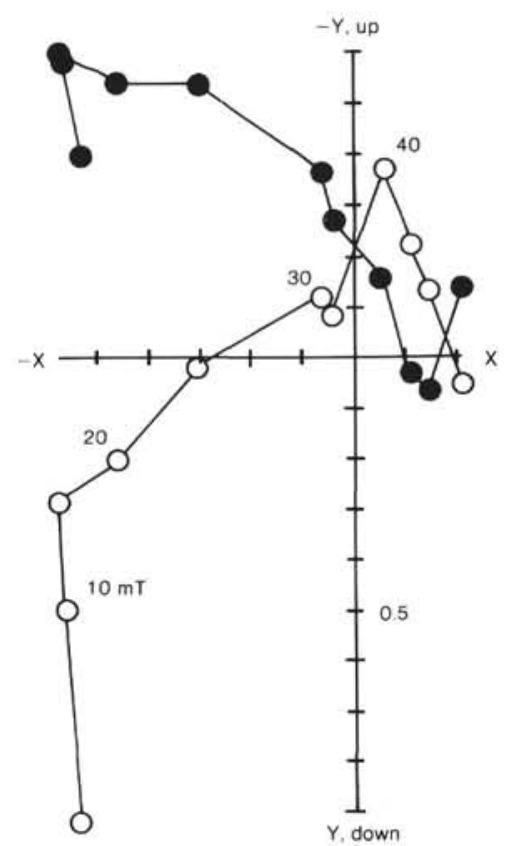

Figure 9. Results of progressive AF demagnetization of stacked specimens from the upper Olduvai transition from Hole 607A plotted as vector endpoint diagrams (see caption to Fig. 1 for further explanation). Units are in $1 \times$ $10^{-3} \mathrm{~A} / \mathrm{m}$. A. From the reversed polarity zone above the transition. B. From the normal polarity zone below the reversal. C and D. From within the transition zone.

reversal removed a steep, downwardly directed component and appeared to isolate successfully a ChRM in each specimen after treatment at 20 to $30 \mathrm{mT}$. Examples of these results plotted as vector endpoint diagrams are shown in Figure 11. The specimen from $40.5 \mathrm{~cm}$ is from a fully reversed polarity zone, whereas the other three specimens are from within the transition zone.
The results obtained after partial demagnetization at $30 \mathrm{mT}$ are presented in Figure 12. The inclinations observed below the reversal are in good agreement with values predicted by a reverse ADF $\left(-67.2^{\circ}\right)$ (mean: decl. $=68.1^{\circ}$, incl. $=65.9^{\circ}, \mathrm{k}=255.1$, alpha $95=2^{\circ}, \mathrm{n}=$ 20 from $90.0-99.5 \mathrm{~cm}$ ). A gradual progression toward normal polarity directions upcore from $80 \mathrm{~cm}$ is seen, 


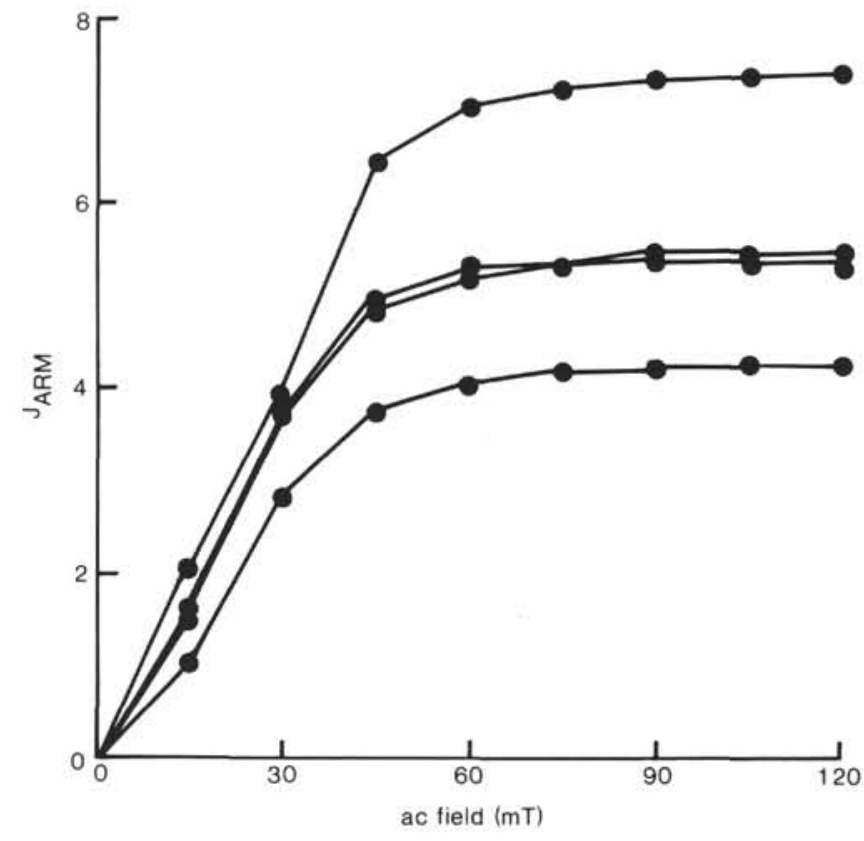

Figure 10. Results of ARM acquisition experiments using specimens from the transition sampled in Hole 609B. (The ARM intensities are plotted in units of $1 \times 10^{-1} \mathrm{~A} / \mathrm{m}$.)

although there is an abrupt offset in the directional data at $64 \mathrm{~cm}$. Above $50 \mathrm{~cm}$ an increase in the between-specimen scatter exists, evident in the declination record because of the very steep inclinations across this interval.

The directional change occurs after a marked drop in the NRM intensity values, although the record is not sufficiently long to determine if the intensity variations are unique to the reversal. As discussed above, the variation in intensity can be a function of a number of unknown variables one of which is field behavior. In an attempt to normalize for variations in the amount of magnetic carrier, these specimens were given ARMs as described above. The NRM and ARM intensities are plotted in Figure 13, together with the ratio of NRM values and ARM values. Although relating the meaning of the ARM variation to the NRM intensities is not necessarily straightforward (King et al., 1982; Bannerjee et al., 1981), these results indicate that at least to a firstorder approximation the NRM intensity variation cannot be attributed solely to downcore changes in the amount of magnetic carrier.

Figure 14 plots the virtual geomagnetic pole (VGP) path calculated for this transition after uniformly reorienting the declination record so that the full reversed polarity mean was equal to $180^{\circ}$. The VGP path is characterized by a longitudinally tightly constrained progression of poles from positions centered near the south geographic pole to approximately $60^{\circ} \mathrm{N}$. This portion of the path is centered about the $270^{\circ} \mathrm{E}$ meridian. The poles then begin to spiral westward before moving toward the north geographic pole by the top of the sampled interval.

\section{Upper Jaramillo}

Progressive AF demagnetization of specimens from the upper Jaramillo transition are plotted in Figure 15.
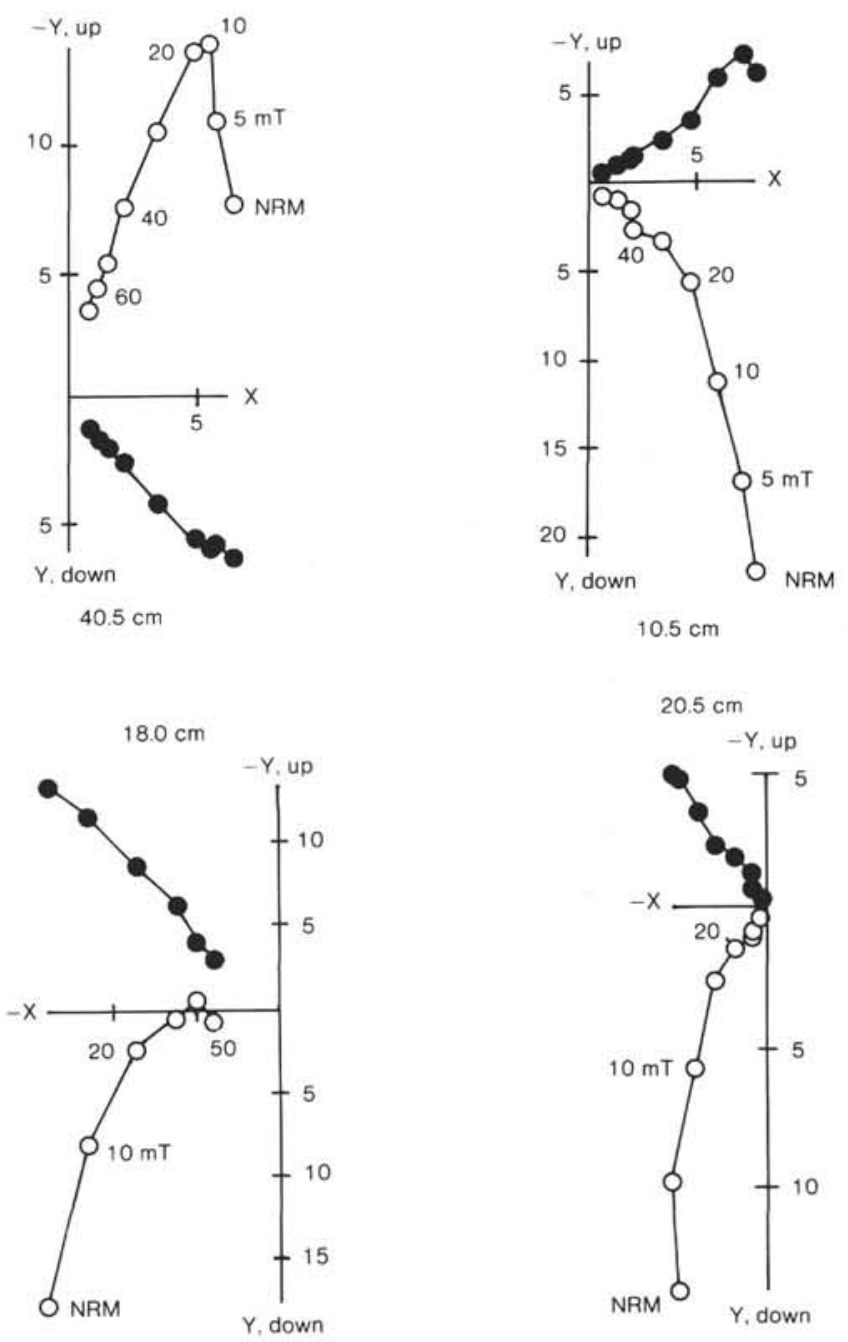

Figure 11. Vector endpoint diagrams illustrating results of progressive AF demagnetization of specimens from the Matuyama-Brunhes transition from Hole $609 \mathrm{~B}$. Units are in $1 \times 10^{-3} \mathrm{~A} / \mathrm{m}$. Note that specimens from $10.5 \mathrm{~cm}, 18.0 \mathrm{~cm}$, and $20.5 \mathrm{~cm}$ exhibit single-component, intermediate directions after removal of a steep downwardly directed component.

Both intermediate and full polarity specimens exhibit univectorial magnetizations.

The upper Jaramillo transition record obtained from Hole 609B is plotted in Figure 16. The directional data exhibit very little between-specimen scatter, even across intervals of intermediate polarity directions. The large amount of internally consistent directional variation across this interval makes it difficult to define the bounds of the transition zone. For example, the $60^{\circ}$ swing in the inclination record centered at $68 \mathrm{~cm}$ may be an excursion or may be part of the transitional behavior. This is further complicated by the presence of large breaks or offsets in the directions that are observed across $0.5 \mathrm{~cm}$. These levels exhibit notable discontinuities in all three records (inclination, declination, and intensity) shown in Figure 16.

The declinations appear to have changed $180^{\circ}$ from $100 \mathrm{~cm}$ to $80 \mathrm{~cm}$, although full normal polarity directions were not observed in the base of the U-channel sample. Unfortunately sampling could not be extended 


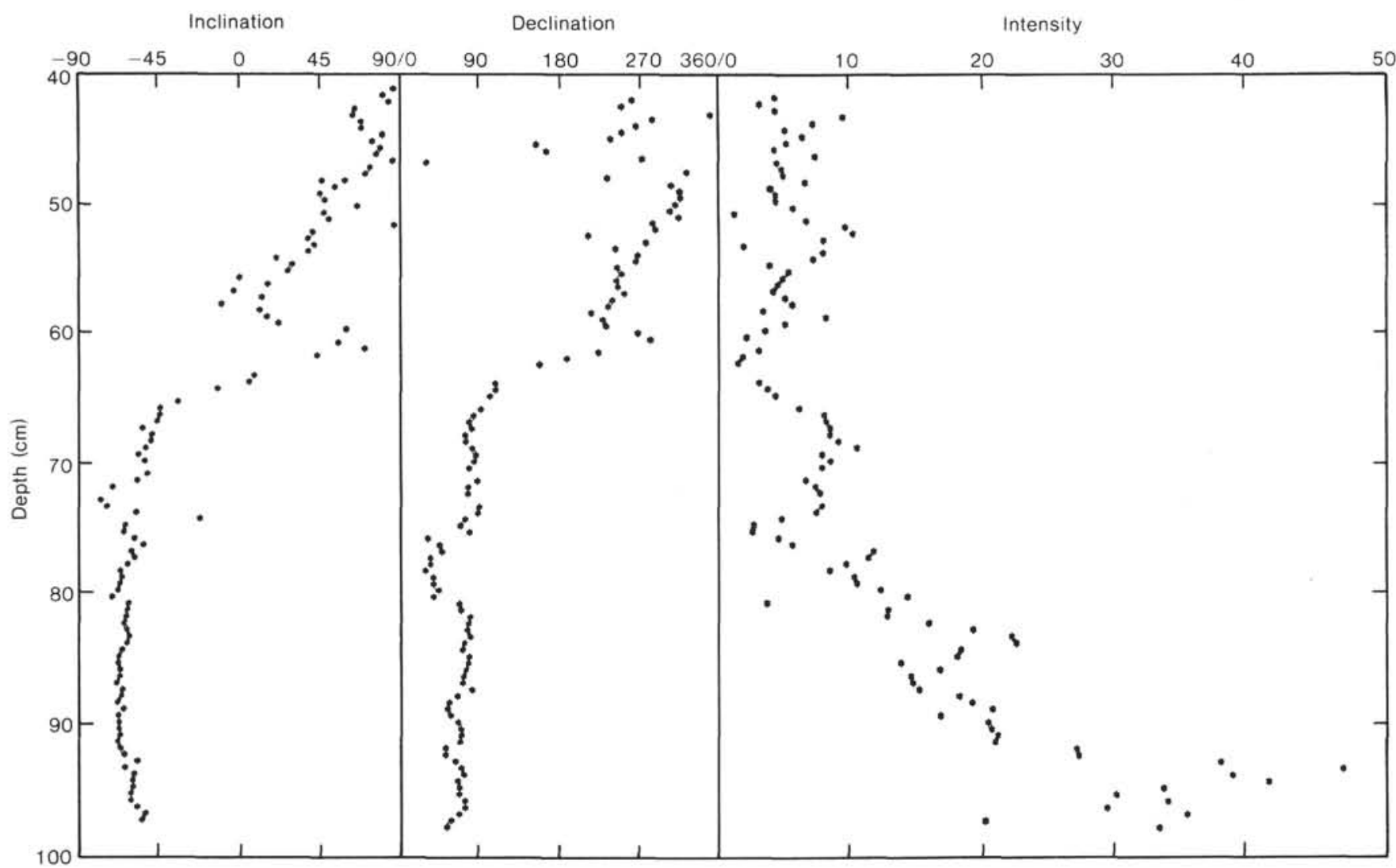

Figure 12. The results obtained from the Matuyama-Brunhes polarity transition from Hole 609B after AF treatment at $20 \mathrm{mT}$ plotted versus depth in section. Intensities are plotted in units of $1 \times 10^{-3} \mathrm{~A} / \mathrm{m}$.

downcore, and therefore the lower boundary of the transition zone cannot be defined.

The NRM intensity record for this interval exhibits a quasiperiodic variation greater than a factor of three downcore. This record is shown in Figure 17 along with the ARM record and the normalized NRM record (NRM/ ARM ratio). The ARM values are not constant but the relative variations seen downcore are not nearly as extreme as those seen in the NRM data. Normalizing the NRM record by the ARM record tends to sharpen the variations, although the low between 30 and $20 \mathrm{~cm}$ is diminished. Comparison of the magnetic records with the core photographs suggests a correlation between highlow intensity and dark-light lithologic variations. Although difficult to quantify further, the appearance of a correlation between the NRM intensity and the lithology places interpretations of the normalized intensity record as a relative paleo-intensity record in doubt.

\section{Lower Jaramillo}

Progressive AF demagnetization of samples from the lower Jaramillo transition record indicates that a stable, univectorial ChRM has been isolated after treatment at $30 \mathrm{mT}$. Examples of demagnetization of four specimens are shown in Figure 18. Specimens from both the transitional as well as full polarity intervals exhibit similar straightforward behavior during progressive AF demagnetization.

The results obtained after AF demagnetization at 30 $\mathrm{mT}$ are shown plotted versus depth in Figure 19. The re- versal is identified by a $180^{\circ}$ directional change that occurs within a broad NRM intensity low. The inclinations above and below the reversal are in excellent agreement with predicted ADF values of $\pm 67.2^{\circ}$. Moving upcore, the inclinations begin to shallow at $100 \mathrm{~cm}$. Above 88 $\mathrm{cm}$ the inclinations steepen upward reaching values of nearly $-80^{\circ}$ before shallowing and passing through the horizontal at $73 \mathrm{~cm}$ and finally settling about the normal polarity mean by $65 \mathrm{~cm}$. The declinations also begin to change at $100 \mathrm{~cm}$, gradually rotating over $50^{\circ}$ by $88 \mathrm{~cm}$. From this depth to $65 \mathrm{~cm}$ an increase in scatter is observed, but above $65 \mathrm{~cm}$ the declinations group tightly around the normal polarity mean. A gradual trend, however, is present in the declination record, which continues to the top of the sampled interval. The NRM intensities decrease upcore from 120 to $88 \mathrm{~cm}$ and remain at this low level until $44 \mathrm{~cm}$ where the values begin to increase again.

A disturbance is seen in the directional and intensity records from 47 to $44 \mathrm{~cm}$. This behavior coincides with the presence of a green foraminiferal sand layer that easily deformed during the subsampling of the U-channel sample. The discontinuities in the directional and intensity records across this interval are interpreted as the results of disturbances caused by sampling.

A comparison of the NRM, ARM, and NRM/ARM records is shown in Figure 20. A significant decreasing trend is observed in the ARM intensity record from 120 to $44 \mathrm{~cm}$, above which the values increase to the top of the sampled interval. The ARM intensity minimum co- 


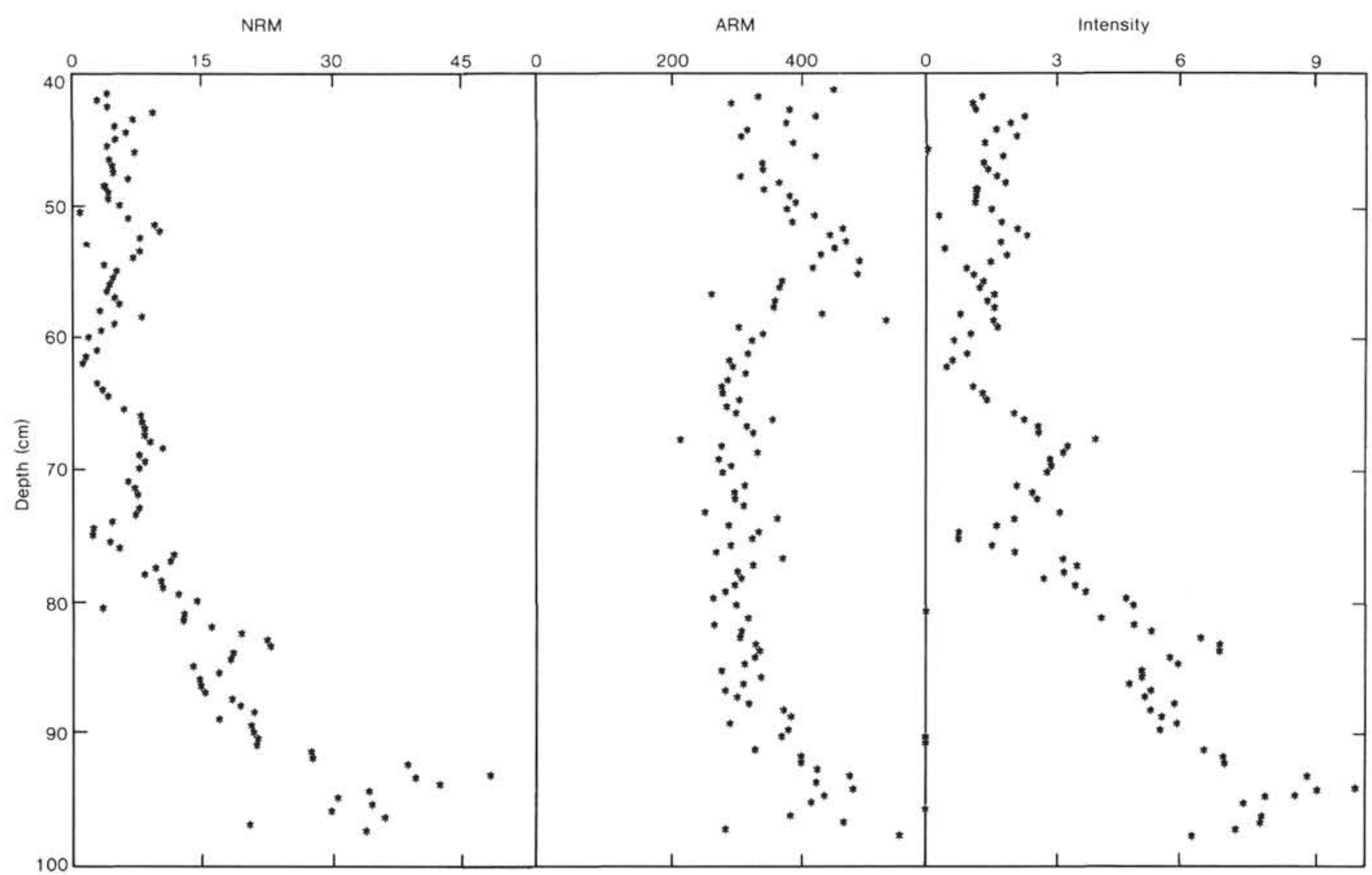

Figure 13. The NRM (at $20 \mathrm{mT}$ ), ARM, and NRM/ARM intensity records from the Matuyama-Brunhes transition from 609B plotted in units of 1 $\times 10^{-3} \mathrm{~A} / \mathrm{m}$.

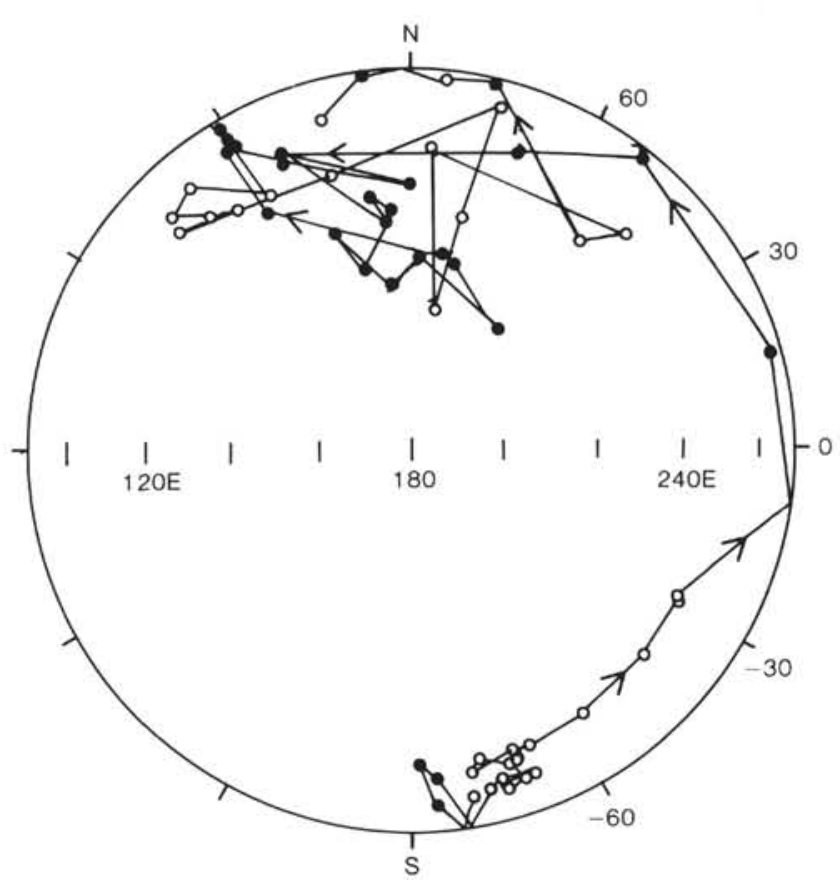

Figure 14. The VGP path calculated for the Hole 609B MatuyamaBrunhes polarity transition plotted on an equal area, equatorial projection. Each VGP was calculated from the directions observed from a 0.5 -cm-thick specimen. incides with the depth of the sand layer. As discussed previously, it is not clear that the ARM method of intensity normalization will effectively remove the effects of changes in the type and or amount of magnetic carrier. The normalized record is included in Figure 20, and it reveals a broad low across this interval, similar to the low in the NRM record, although samples from the sandy layer at 47 to $44 \mathrm{~cm}$ still exhibit low values relative to the adjacent specimens. Interpreting this intensity record in terms of geomagnetic field behavior is not straightforward, but the NRM record is not identical to the ARM record and therefore the low in the normalized record cannot be readily interpreted as a product of lithologic variations only.

The VPG path was calculated for this reversal using a 3 -point running unit vector mean of the directional record. This path is plotted in Figure 21. The path is roughly centered about the $180^{\circ}$ meridian, being longitudinally constrained very early in the reversal and then looping in a counterclockwise direction centered about $220^{\circ} \mathrm{E}$, $40^{\circ} \mathrm{S}$. The VGPs then move westward to the vicinity of $25^{\circ} \mathrm{N}, 140^{\circ} \mathrm{E}$, after which they move eastward toward the north geographic pole.

\section{Upper Olduvai}

Examples of the results of progressive AF demagnetization of specimens from the upper Olduvai transition are shown in Figure 22 plotted as vector endpoint dia- 

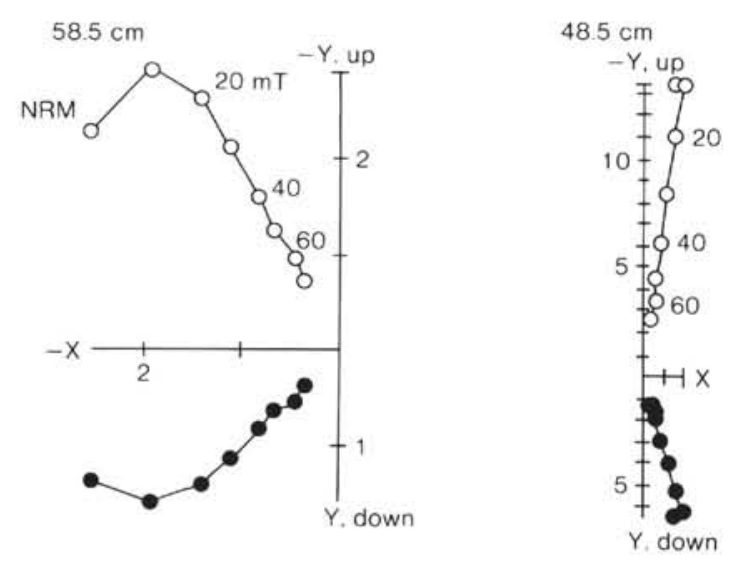

$65.5 \mathrm{~cm}$
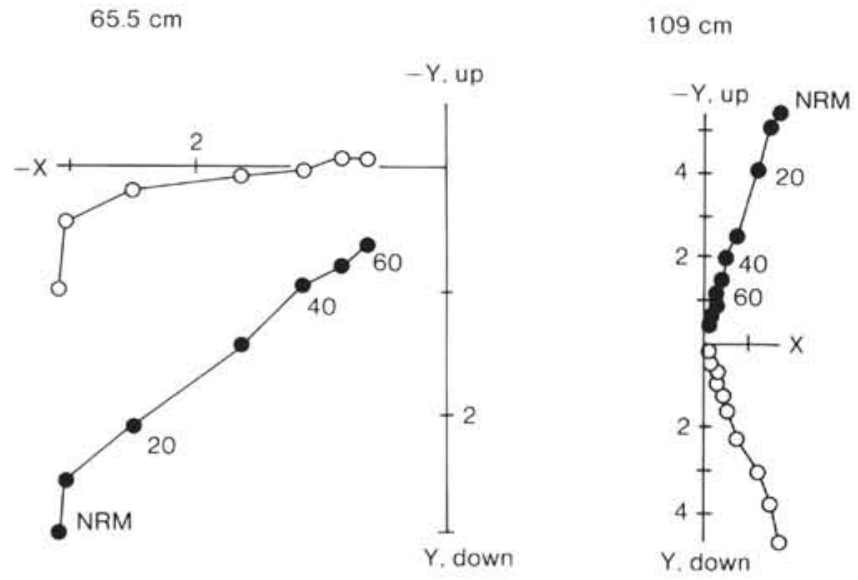

Figure 15. Vector endpoint diagrams showing behavior of specimens from the upper Jaramillo transition from Hole 609B during progressive AF demagnetization. Units are in $1 \times 10^{-3} \mathrm{~A} / \mathrm{m}$.

grams. These results indicate that a downwardly directed component is effectively removed after treatment at low fields (as seen in specimens from other sections from this site), isolating a component that decays toward the origin with treatment at higher peak fields. After treatment at peak fields of $20 \mathrm{mT}$ a component is observed in close agreement with predicted ADF values $\left(67.2^{\circ}\right)$ in specimens from below $95 \mathrm{~cm}$. Above this depth, however, this treatment isolates well-defined components characterized by intermediate directions.

The transition record after partial demagnetization at $20 \mathrm{mT}$ is presented in Figure 23. Apparently, a complete record of the reversal was not obtained, and it was not possible to sample further upcore in this section. The inclinations remain grouped about the unit vector mean $\left(63.6^{\circ}\right)$ from 150 to $95 \mathrm{~cm}$. Above this depth the inclinations shallow, passing through the horizontal, and steepen upwards reaching values of $-77^{\circ}$ by $75 \mathrm{~cm}$. The directions then shallow, pass through the horizontal again (reaching values of $+70^{\circ}$ by $65 \mathrm{~cm}$ ), and progress to values of $-69^{\circ}$ by the top of the sampled interval at $50 \mathrm{~cm}$. The declination record exhibits a nearly $450^{\circ}$ progression across this interval. Two abruptly discontinuities are evident in the declination record, one of which is apparent in the inclination record as well. Across these discontinuities the directions change by as much as $120^{\circ}$ between stratigraphically adjacent specimens. The break in the direction record at $95 \mathrm{~cm}$ is not accompanied by a significant increase in the total vector dispersion in the records, although the break at $65 \mathrm{~cm}$ is accompanied by an increase in scatter in the inclinations. These breaks do not coincide with physical breaks or twists in the core. A simple core twist would not explain the observed directional geometries because the inclinations would not be affected by a twist.

The NRM intensities across this interval steadily decrease from 150 to $115 \mathrm{~cm}$ and remain at this low level to the top of the section. Figure 24 shows the NRM, ARM, and the normalized NRM records. Significant variations are seen in the ARM record, but the relative magnitudes of these changes are not sufficient to account for the variation in the NRM record. This is made clear by the similarity between the NRM record and the NRM/ARM records plotted in Figure 24.

The VGP path calculated for this polarity transition is shown in Figure 25. Before calculating the VGPs, the entire declination record was uniformly reoriented so that the mean declination of the full normal polarity zone below $140 \mathrm{~cm}$ was equal to $0^{\circ}$. The VGPs were then calculated from a 3-point running unit vector mean of the directional data. Although segments of the VGP path are longitudinally constrained, the path in its entirety exhibits both near-sided and far-sided behavior. This transition record appears to record three consecutive transitions as the VGP path passes from the north geographic pole to the south and then back to close to the north geographic pole again, before approaching the south geographic pole in the uppermost portion of the record.

\section{DISCUSSION}

Of the eleven polarity transitions presented above, only the four records from Hole 609B meet the basic criteria that allow interpretation of these data as records of transitional field behavior. The remaining records failed to record accurately the full polarity directions, were characterized by a lack of internal consistency through the transition zone, or the observed intermediate directions were determined to be products of multicomponent magnetizations that are not readily interpreted in terms of geomagnetic field behavior. Some of these records, for example, the Matuyama-Brunhes from Holes $606 \mathrm{~A}$ and 610C, appear to contain transitional field information but the incomplete removal of the steep, downward component causes a scatter in the intermediate directions that obscures the details of the transitional record.

\section{Durations}

The durations calculated from the Matuyama-Brunhes transitions can be used to examine the latitudinal dependence of durations (Clement and Kent, 1984b). Of the lower sedimentation rate records, only the one from Hole $606 \mathrm{~A}\left(37^{\circ} \mathrm{N}\right)$ exhibits intermediate directions bounded by full normal and full polarity zones. The duration of the directional change in this record is 4500 yr. A minimum duration estimate can be obtained from the Hole $610 \mathrm{C}$ transition. If the entire $70-\mathrm{cm}$ section from 


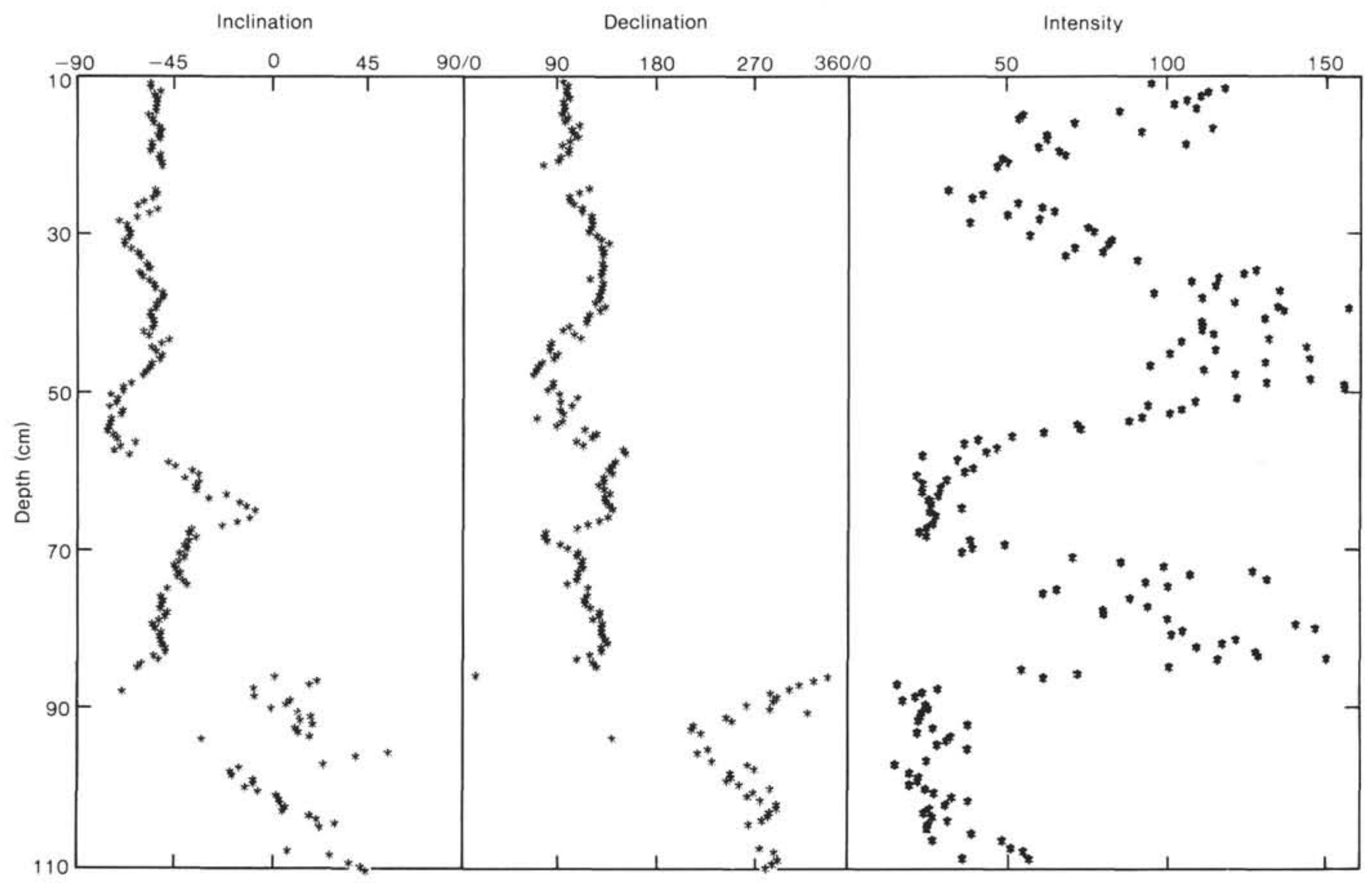

Figure 16. The results after AF demagnetization at $20 \mathrm{mT}$ of the Hole 609B upper Jaramillo transition, plotted versus depth in section. Intensities are plotted in units of $1 \times 10^{-3} \mathrm{~A} / \mathrm{m}$.

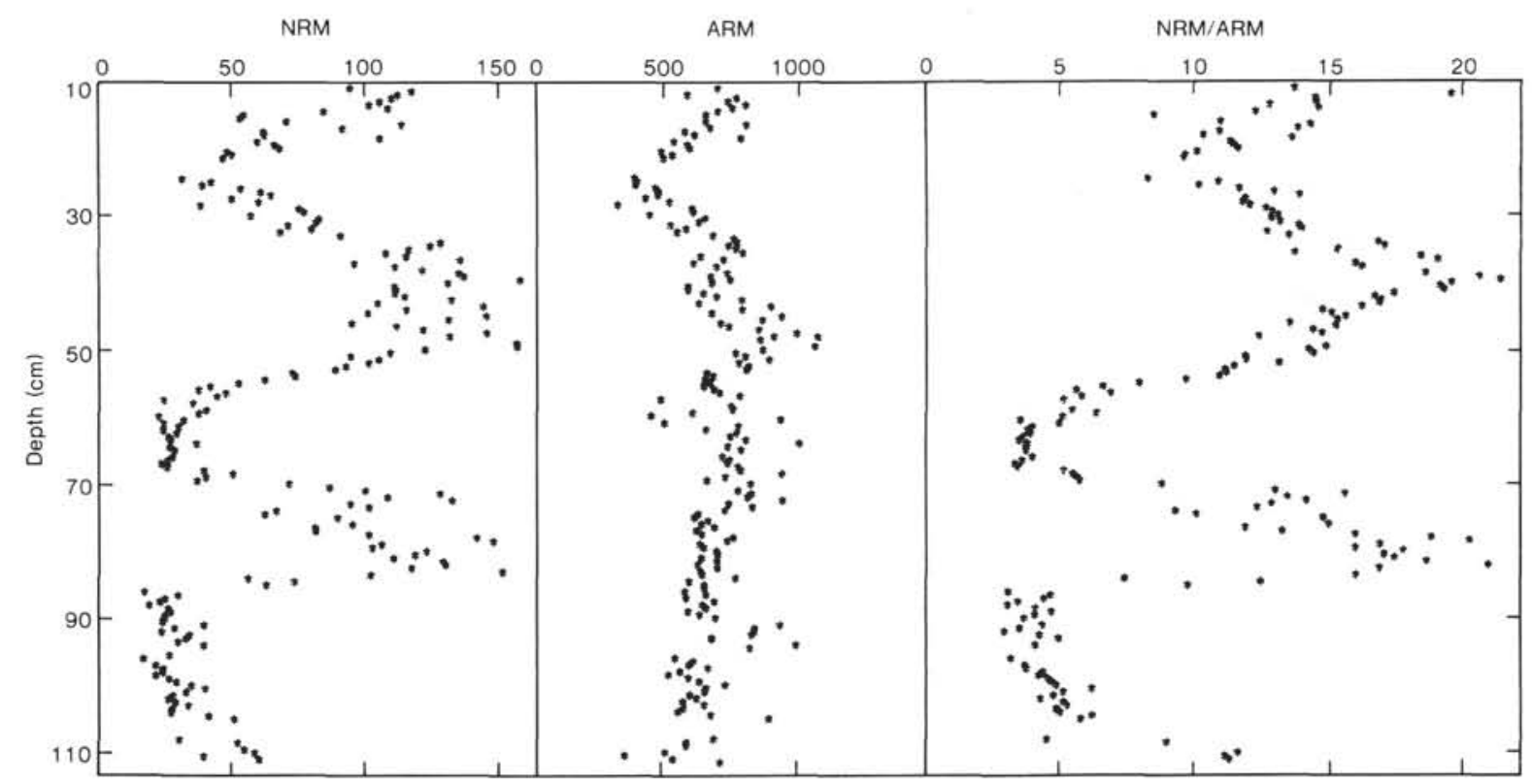

Figure 17. The NRM, ARM intensity records and the NRM to ARM ratio plotted versus depth in section (intensities are plotted in units of $1 \times 10^{-3} \mathrm{~A} / \mathrm{m}$ ). 

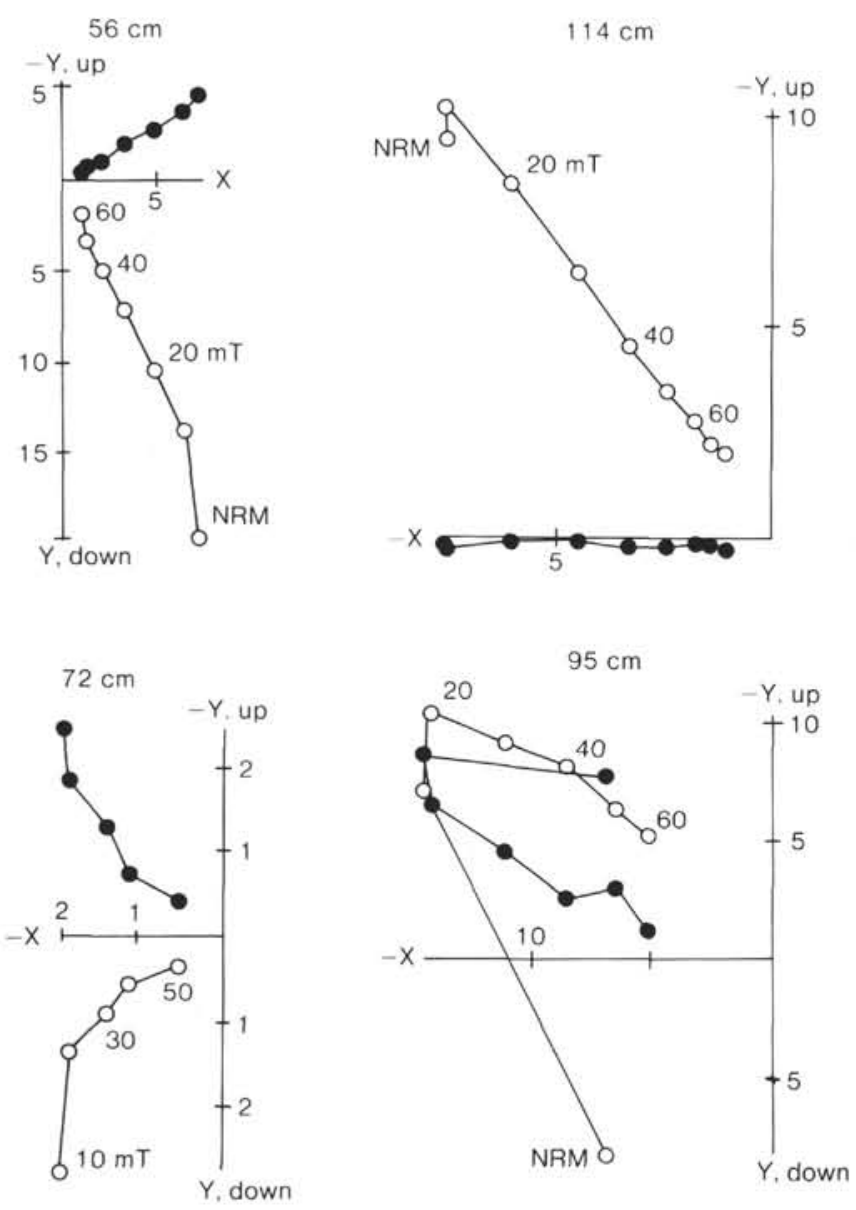

Figure 18. Vector endpoint illustrating the behavior of both full polarity and intermediate specimens from the lower Jaramillo transition from Hole 609B. Units are in $1 \times 10^{-3} \mathrm{~A} / \mathrm{m}$.

Hole $610 \mathrm{C}\left(53^{\circ} \mathrm{N}\right)$ is interpreted as representing intermediate directions, then a duration of 12,000 yr. is estimated. These durations exhibit a latitudinal dependency in the same sense as the low sedimentation rate cores from the Pacific, but the difference is much larger. The incomplete nature of the other Matuyama-Brunhes transitions obtained from the Leg 94 sediments, including the record from Hole 609B discussed below, makes the latitudinal dependence of the durations less apparent. The difference between the Atlantic and Pacific cores may be suggesting a longitudinal dependence, although a rigorous examination is not merited with the given data set.

The detailed directional records obtained from Hole 609B suggest that the durations of the transitions are more tightly constrained. Sedimentation rates may not be continuous on the sampling scale used here, but appear to be when averaged over longer intervals. The rate in Hole 609B appears to be nearly constant at $82.5 \mathrm{~m}$ / $\mathrm{m} . \mathrm{y}$. from the top of the Olduvai subchronozone to the base of the Brunhes chronozone. This rate may be used at least to provide some limits on the duration of the transitions observed at this site.

The Matuyama-Brunhes directional change occurs across at least $26 \mathrm{~cm}$ (the top of the transition zone was not sampled), thus a minimum duration for this reversal is $3200 \mathrm{yr}$. The sedimentation rate curves from the holes cored at Site 609 exhibit an inflection at the MatuyamaBrunhes reversal with slower rates above and faster rates below. If only the origin (the mudline set at depth $=0$, age $=0$ ) and the depth of the Matuyama-Brunhes reversal are used to calculate a sedimentation rate, a rate of $58.5 \mathrm{~m} / \mathrm{m}$.y. is obtained. This rate yields a duration estimate of $4400 \mathrm{yr}$.

The lower Jaramillo reversal occurs across a minimum thickness of $34 \mathrm{~cm}$, which in turn yields a duration of $4100 \mathrm{yr}$. The upper bound of the directional change is difficult to pick because there is a trend in the declination record in the upper interval of this section, but it is interrupted by the disturbed zone associated with the sand layer at 44 to $47 \mathrm{~cm}$. A complete $180^{\circ}$ change in the declinations is not reached until the top of the sampled interval. If this entire interval is interpreted as recording intermediate directions, the transition zone is $69 \mathrm{~cm}$ thick, corresponding to $8400 \mathrm{yr}$. Without a further extension of the record upcore it is not possible to determine if this declination variation is transitional or typical of that observed in full polarity intervals.

The upper bound of the upper Olduvai reversal was not observed within the sampled interval. Therefore only a minimum estimate of the duration can be made. The transition zone is at least $47 \mathrm{~cm}$ thick, which results in a minimum estimate of 5200 yr. duration.

The NRM intensity records for these reversals exhibit broad lows associated with the directional change, with the exception of the upper Jaramillo. Attempts were made to normalize these intensity records with the ARM records to minimize possible lithologic effects, but this attempt appears not to have been completely successful. For example, in the case of the upper Jaramillo the large intensity variations may be correlated to lithologic variations. In the other three records a broad low is observed in both the NRM and normalized intensity records, with the minimum intensities commonly 5 to $10 \%$ of those observed toward the ends of the sections. In each of these sections the intensity is not long enough to establish the total thickness of the intensity variation associated with the polarity transition. The intensity low in each of these reversals, however, is recorded across a significantly longer section than the directional change and generally is recorded across a minimum of $1 \mathrm{~m}$ section.

\section{Continuity of Records}

The high sedimentation rate $(82.5 \mathrm{~m} / \mathrm{m}$.y. $)$ at Hole 609B allows considerable detail to be observed in the transition zones of each of the four reversals sampled at this site. The upper Jaramillo record differs from the others in that large amplitude swings are observed in the directional record well above the level at which the transition zone boundary would be placed using the definition based on the circular standard deviation of the full polarity directions (Clement and Kent, 1984b).

The intensity record from this hole exhibits large changes above this level, which may be correlated to lithologic changes (see Fig. 17). These features suggest that the sedimentation rate across this interval may not have been 


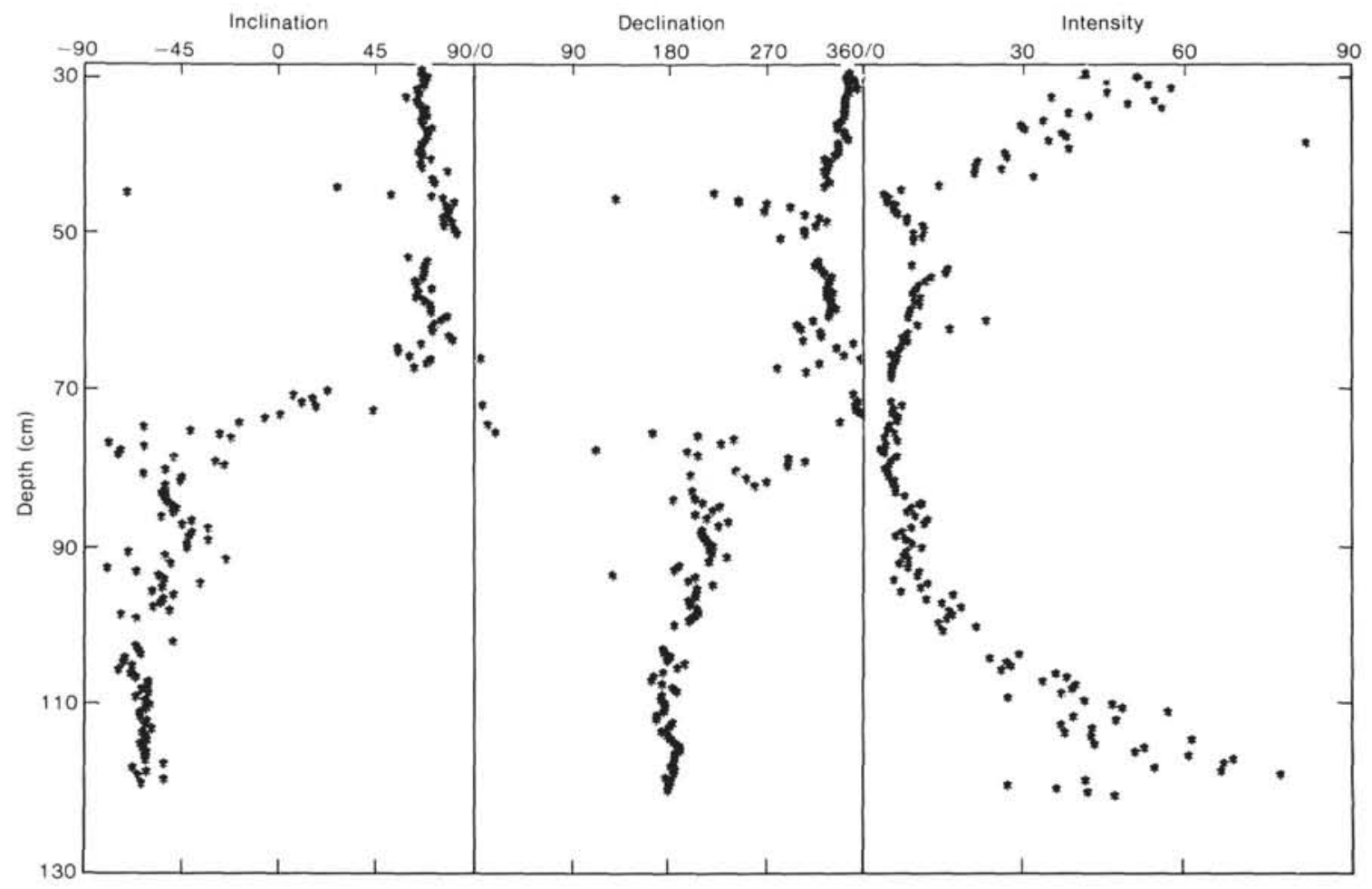

Figure 19. Inclination and declination $\left({ }^{\circ}\right)$, and NRM intensity records of the Hole 609B lower Jaramillo transition plotted versus depth in section. The intensities are plotted in units of $1 \times 10^{-3} \mathrm{~A} / \mathrm{m}$.

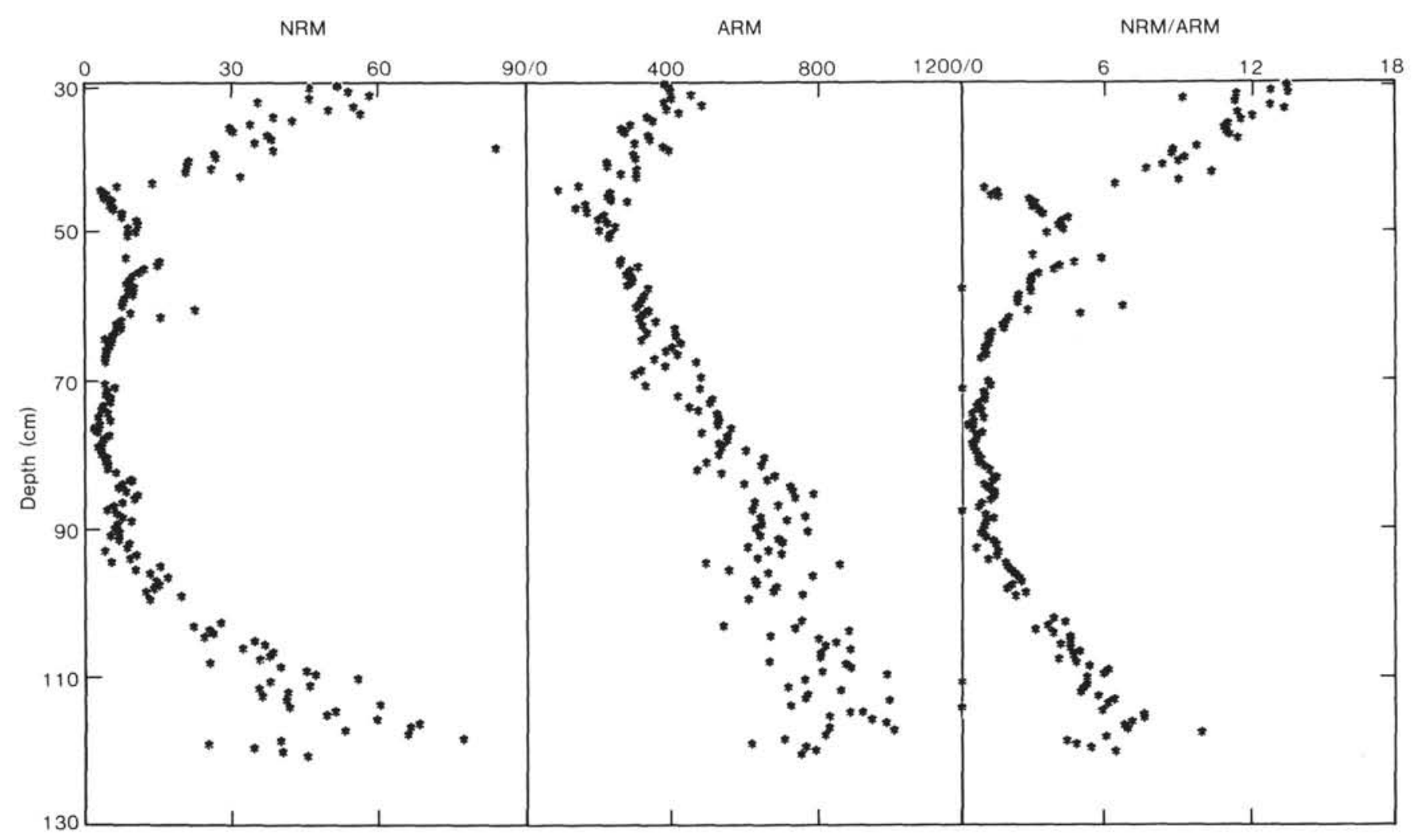

Figure 20. The NRM, ARM intensity records and the NRM to ARM ratio observed across the lower Jaramillo transition from Hole $609 \mathrm{~B}$ plotted in units of $1 \times 10^{-3} \mathrm{~A} / \mathrm{m}$. 


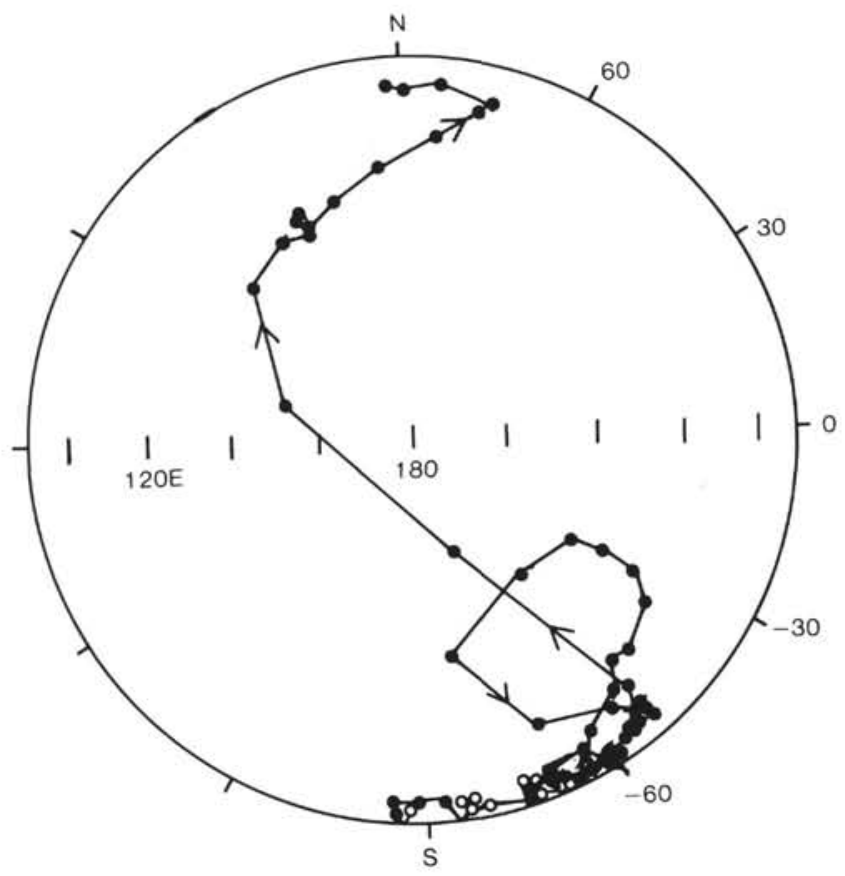

Figure 21. The VGP path calculated from the Hole 609B lower Jaramillo transition plotted on an equal area, equatorial projection; open symbols represent projection onto the far hemisphere, closed symbols, projection onto the near hemisphere.

constant. If this is the case, then the directional record above the reversal may represent a high resolution record of secular variation, whereas discontinuous sedimentation in the lower interval resulted in an incomplete record of the reversal.

Likewise, the upper Olduvai transition record contains two abrupt discontinuities in the directional record. The breaks in the magnetic records do not coincide with visible disturbances or physical breaks in the core. These discontinuities may be interpreted as very rapid changes in the transitional field, or they may represent breaks in the magnetic records caused by hiatuses. Distinguishing interruptions in the deposition and rapid field changes is difficult, although these discontinuities are defined by large directional changes occurring between stratigraphically adjacent, 0.5 -cm-thick samples. If the field changed so rapidly, a smearing of the record would be expected unless the remanence lock-in zone was considerably thinner than sample thickness. The lack of increased dispersion associated with these levels argues that these levels more likely represent erosional surfaces. Because the directions on either side of the breaks are not the result of multicomponent magnetizations, it is difficult to ascribe these discontinuities to large directional changes caused by small changes in the relative magnitude of two or more widely divergent and overlapping components. The gradual directional progression above and below these levels indicates that even in pelagic depositional environments sedimentation rates cannot be assumed to be continuous on the scale of this study.

The occurrence of intermediate directions on both sides of these levels constrains the amount of time that may be missing in the hiatuses to significantly less time
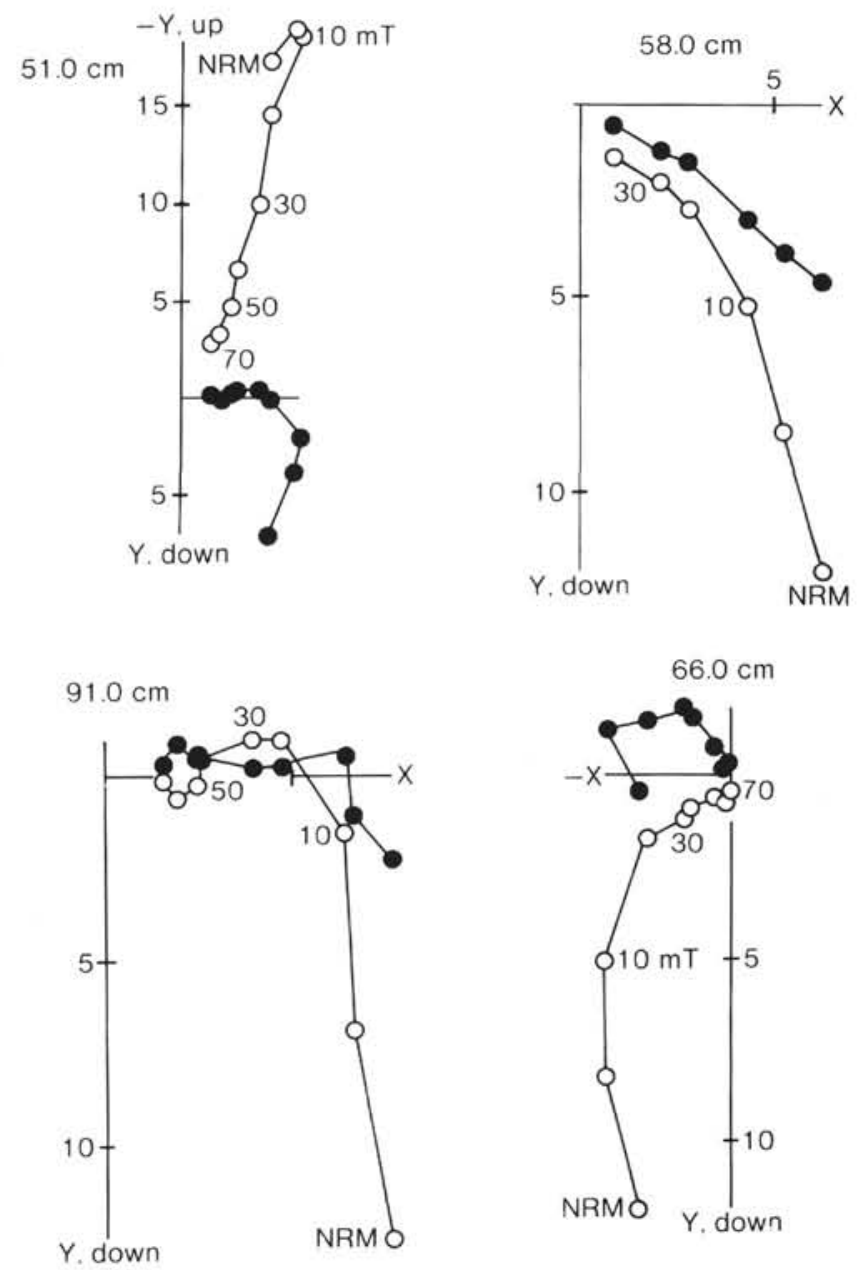

Figure 22. Results of progressive AF demagnetization of specimens from the upper Jaramillo transition from Hole 609B plotted as vector endpoint diagrams. Units are in $1 \times 10^{-3} \mathrm{~A} / \mathrm{m}$.

than it takes for the field to reverse. Transition durations are currently thought to be on the order of 5000 to 10,000 yr. (Clement and Kent, 1984b). If it is assumed that the rate of change of the field remains constant, the observed directional change across these discontinuities can be used to obtain estimates of the amount of the record missing. For the upper Olduvai from Hole 609B it appears that each break represents approximately 1000 yr. The fact that two of these discontinuities occur within $30 \mathrm{~cm}$ in the upper Olduvai transition indicates that short hiatuses may occur very frequently in sediment previously thought to be characterized by continuous sedimentation.

\section{Transitional Field Models}

The Matuyama-Brunhes polarity transition has been studied at many sites and this reversal has been well documented (Fuller et al., 1979; Clement et al., 1982). Comparison of two of these records, from the Boso Peninsula (Niitsuma, 1971) and Lake Tecopa (Hillhouse and Cox, 1976), demonstrated that the geomagnetic field did not maintain a simple dipolar symmetry during the reversal. This conclusion is supported by the transition records that have been obtained subsequently (Fuller et al., 1979). 


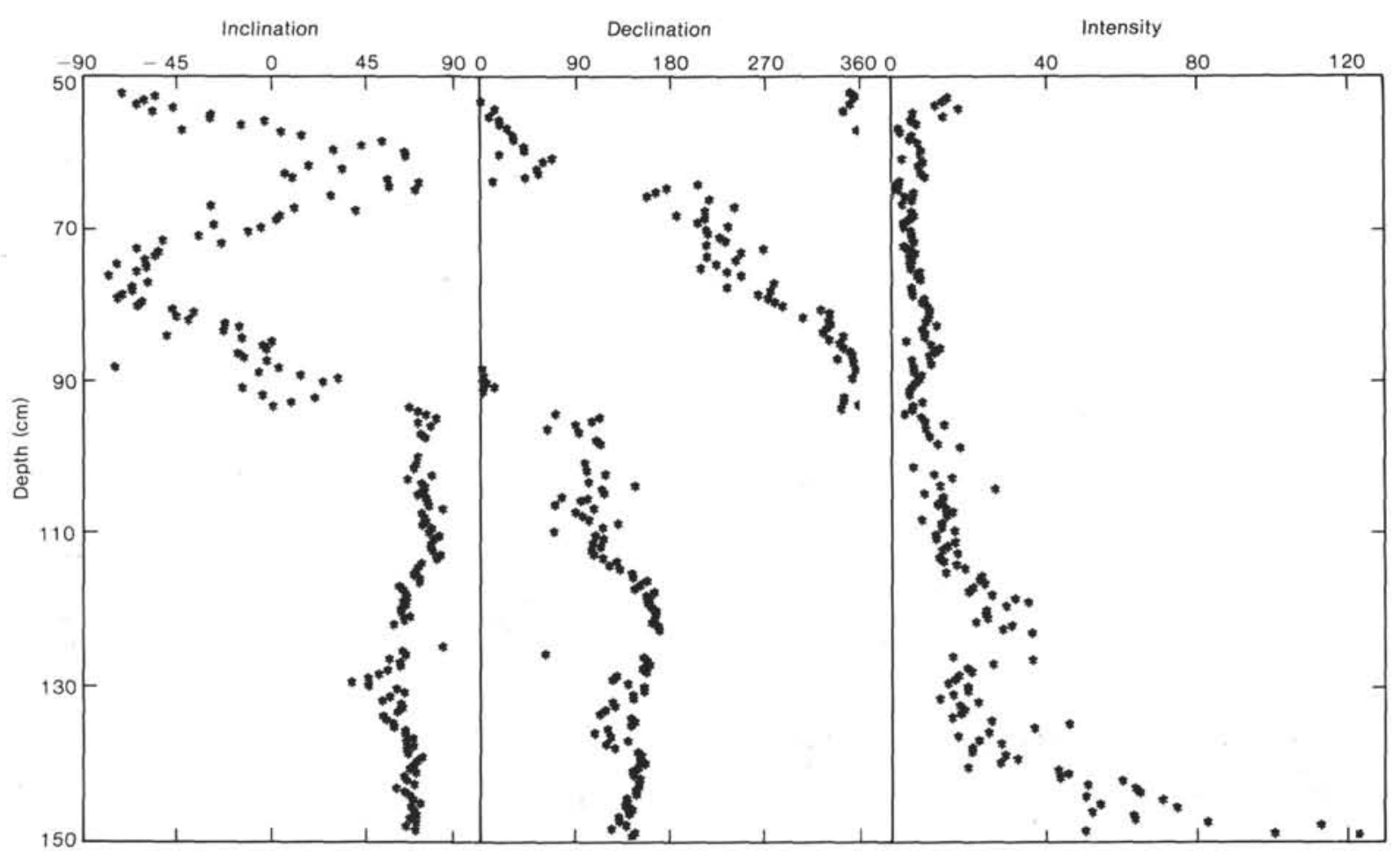

Figure 23. The results from the Hole 609B upper Olduvai transition plotted versus depth in section. The intensities are plotted in units of $1 \times 10^{-3} \mathrm{~A} / \mathrm{m}$.

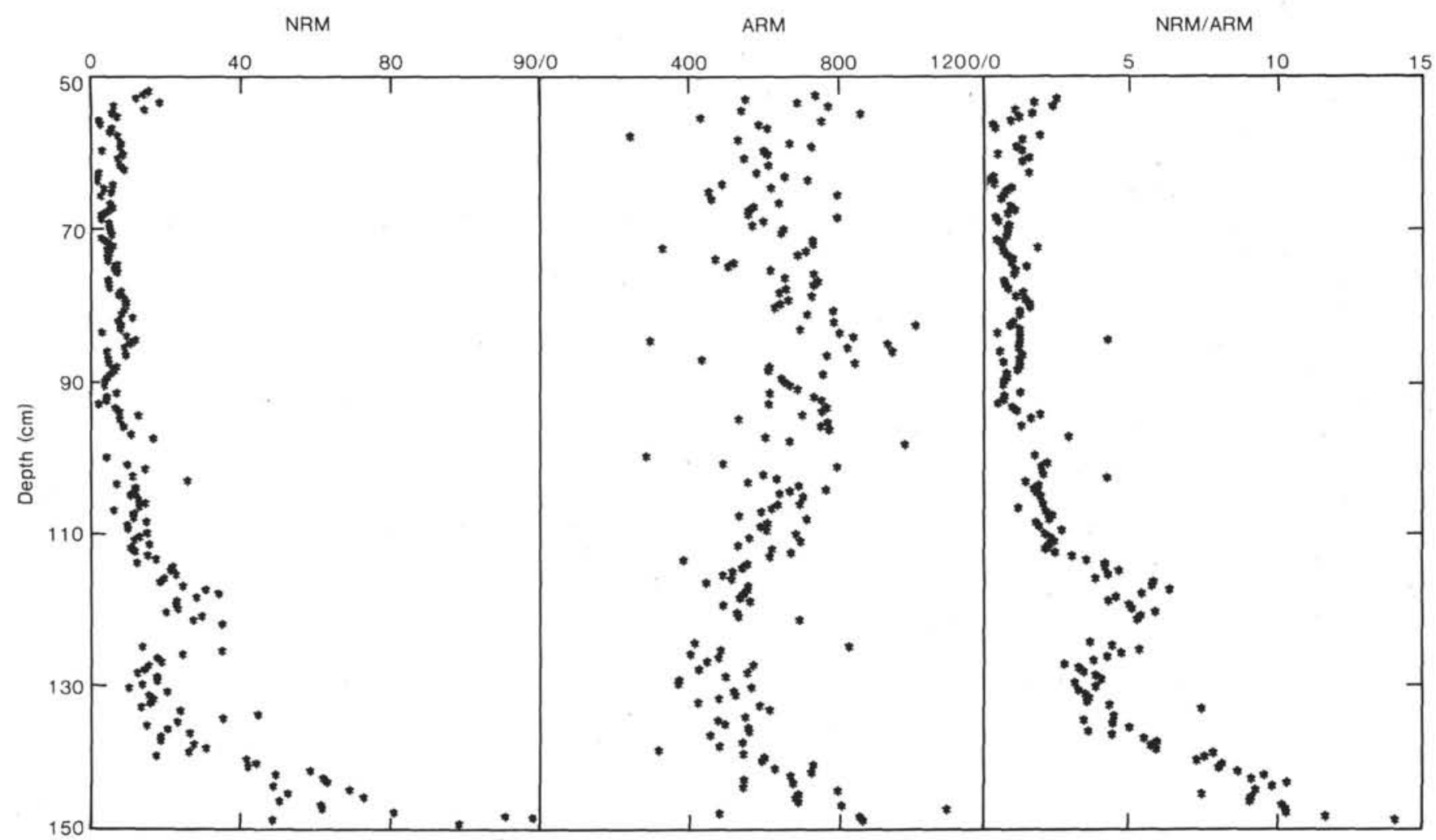

Figure 24. Intensity records of the upper Olduvai transition in Hole 609B showing NRM, ARM, and the ratio of NRM to ARM values plotted versus depth in section, plotted in units of $1 \times 10^{-3} \mathrm{~A} / \mathrm{m}$. 


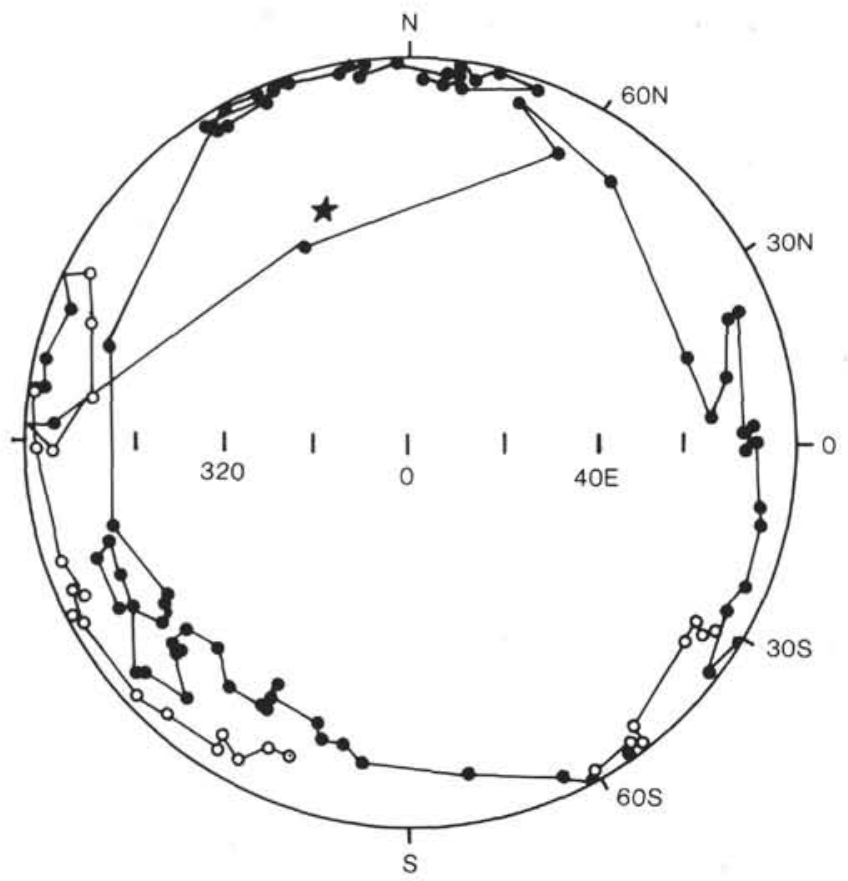

Figure 25. The VGP path from the Hole 609B upper Olduvai (reverse to normal) polarity transition plotted on an equal area, equatorial projection. The site location is indicated by the star. Open symbols represent projection onto the far hemisphere, closed symbols, projection onto the near hemisphere.

Comparison of the VGP path for the transition record from Hole 609B with other available VGP paths obtained at different sites reveals an interesting similarity. The early portion of the Hole 609B VGP path is centered about the $270^{\circ} \mathrm{E}$ meridian as the VGP positions move from near the south geographic pole to high northern latitudes. A number of other VGP paths from Matuyama-Brunhes transitions are centered over the Americas $\left(230\right.$ to $\left.300^{\circ} \mathrm{E}\right)$, at least during the early portions of the transitions. These transitions include results from two north Pacific cores, V20-108 and V20-107 (Clement et al., 1982), results from two cores from the eastern Pacific (Freed, reported in Fuller et al., 1979), and the early portion of the Lake Tecopa record (Hillhouse and Cox, 1976). These paths are illustrated in Figure 26. The Boso Peninsula path falls nearly $180^{\circ}$ away from these other paths (Niitsuma, 1971), indicating that the transitional field was not dipolar. The combined data set for this reversal still exhibits the near-sided site dependence noted by Hoffman (1977) and Fuller et al. (1979). The VGP paths also appears to be longitudinally constrained, although the latter portion of the Hole 609B path, the V20-108, and the Lake Tecopa records exhibit large longitudinal swings that do not appear to coincide.

Longitudinally constrained VGP paths, directly over the observation site or its antipode, are consistent with models based on the assumption that the transitional field is purely axisymmetric (Hoffman, 1977; Williams and Fuller, 1981) or nearly so (Hoffman, 1979). Longitudinally constrained paths suggest a predominance of axisymmetric fields, but if the path is off-site from the site latitude, the presence of nonaxisymmetric terms is indicated. The longitudinally constrained portion of the Hole $690 \mathrm{~B}$ path is centered about the $270^{\circ} \mathrm{E}$ meridian or $60^{\circ}$ away from the site longitude and therefore is nearsided. This agrees with the other available transition records of this reversal but does not further constrain Hoffman's (1977) axisymmetric flooding model.

Testing the Williams and Fuller model (1981) with this record is difficult because the transition record is not complete. The inclination record, however, does exhibit extremely steep, positive values late in the reversal, that is, after the directions have passed through the horizontal. To this extent this record supports the Williams and Fuller (1981) model-developed on five records of the Matuyama-Brunhes reversal-in which the energy lost by an exponentially decaying dipole term in a spherical harmonic expansion of the field was partitioned among the three next low-order nondipole terms. In this version of their model the energy was partitioned with 20,30 , and $50 \%$ going to $+\mathrm{G}_{2}^{\circ},-\mathrm{G}_{3}^{\circ}$, and $+\mathrm{G}_{4}^{\circ}$, respectively.

Only two other detailed records of the lower Jaramillo polarity are currently available for comparison with the results from Hole 609B. One record is from continental sections in Turkmenia (Gurarii, 1981) and the other is from a Southern Hemisphere deep-sea core, RC1414 (Clement and Kent, 1984a). The VGP paths from the Turkmenia sections are roughly centered about the $300^{\circ} \mathrm{E}$ meridian and exhibit a westward progression through the reversal. The VGP paths from RC14-14 and Hole 609B are very similar in that both are centered about the $180^{\circ}$ meridian, and they both exhibit a westward progression through the reversal, as does the Turkmenia record. The similarity between the Hole 609B and RC14-14 records suggests the presence of large-scale symmetries, but the differences in the record obtained from Turkmenia, located in the Northern Hemisphere at nearly the same longitude as the $\mathrm{RC14}-14$ record, indicates that the lower Jaramillo field was not dipolar.

The upper Olduvai transition records from Hole 609B and RC14-14 (Clement and Kent, 1984a) represent the only two detailed records of this reversal currently available. Comparison of the VGP paths from these two records reveals very little similarity, indicating that this reversal was dominated by a nondipolar transitional field. The VGP path from Hole 609B is characterized by segments that are longitudinally constrained and are roughly centered either about the $270^{\circ}$ meridian or the $90^{\circ}$ meridian. Although this behavior appears to support the presence of a predominantly axisymmetric transitional field, these segments are not centered about the site's meridian or its antipode, and the large latitudinal swings (3 distinct equatorial crossings) suggest that the field is more complicated than axisymmetric models imply. The longitudinal constraints of this VGP path directly contradict the longitudinal spiralling observed in the VGP path from the Southern Hemisphere site. These differences suggest that high-order, nondipole terms are necessary to describe this transitional field completely.

Although significant differences exist in the lower Jaramillo and upper Olduvai transitions from Northern and Southern Hemisphere sites, important similarities 


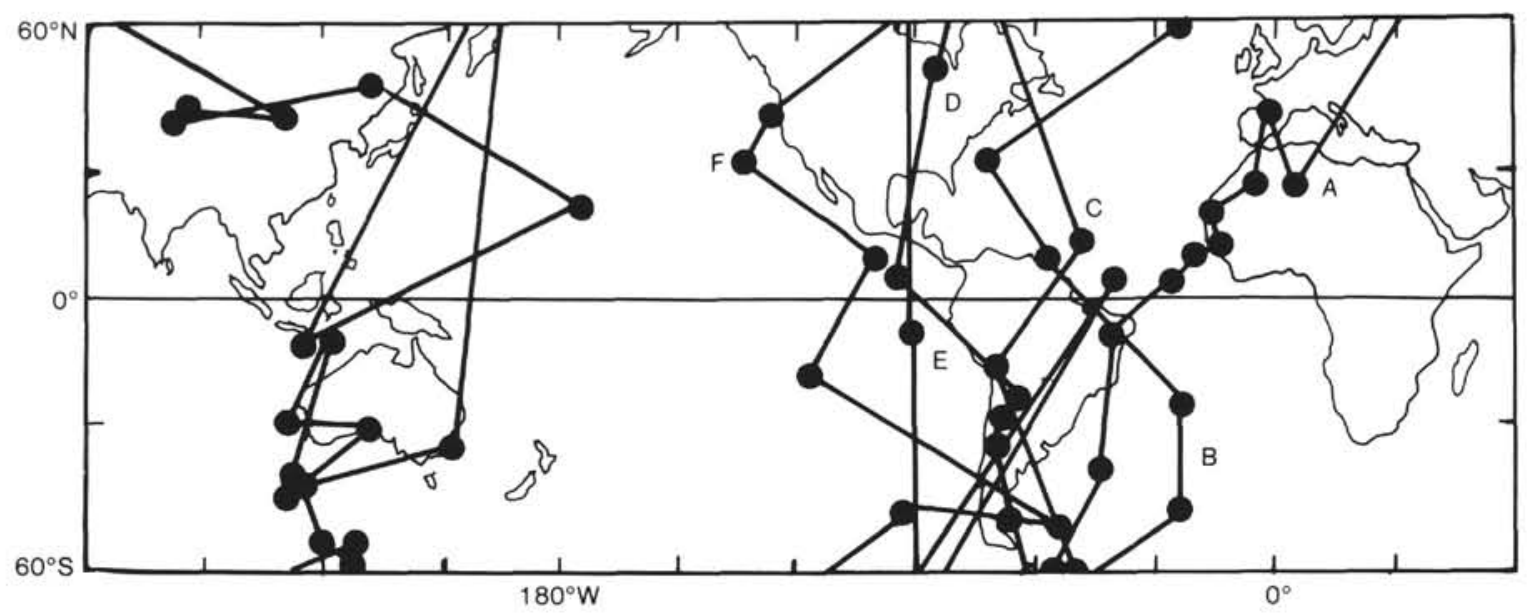

Figure 26. VGP paths from Matuyama-Brunhes transition records. $\mathrm{A}=$ Lake Tecopa; $\mathrm{B}$ and $\mathrm{C}=$ eastern Pacific; $\mathrm{D}=\mathrm{Hole}$ $609 \mathrm{~B} ; \mathrm{E}=\mathrm{V} 20-107$; and $\mathrm{F}=\mathrm{V} 20-108$.

also exist, particularly in the inclination records. All inclinations pass through steep negative values. The timing of the steep directions with respect to the occurrence of horizontal directions is antisymmetric, both about the equator and about the sense of reversal. In the Northern Hemisphere records (Hole 609B), steep directions are observed late in the Normal $(\mathrm{N})$ to Reversed $(\mathrm{R})$ reversal (upper Olduvai) and early in the $\mathrm{R}$ to $\mathrm{N}$ reversal (lower Jaramillo). The Southern Hemisphere records (RC14-14), however, exhibit steep directions early in the $\mathrm{N}$ to $\mathrm{R}$ reversal (upper Olduvai) and late in the $\mathrm{R}$ to $\mathrm{N}$ transition (lower Jaramillo). If the declination records are ignored and these records are assumed to be dominated by axisymmetric fields, the data could be summarized as four transitions exhibiting far-sided VGP paths. Because sites from both hemispheres are included as well as both senses of reversal, these data allow Hoffman's and Hoffman's and Fuller's zonal flooding model $1977 ; 1978$ ) to be fully constrained (see Fig. 27). Within the context of this model the data indicate that both transitional fields were dominated by a quadrupole geometry. This implies that the reversal was initiated in the Southern Hemisphere in the upper Olduvai reversal, and in the Northern Hemisphere in the lower Jaramillo reversal. Thus not only is the first-order geometry of the transition field defined, but it is apparent that the hemisphere in which the reversal is initiated is dependent upon the sense of the reversal.

These records can also be modeled using the more descriptive model developed by Williams and Fuller (1981). Southern Hemisphere transition records (Clement and Kent, 1984b, 1985) were previously modeled using a version of this model in which the energy lost by the dipole was partitioned amongst the low-order zonal nondipole terms with 20,30 , and $50 \%$ going to $-\mathrm{G}^{\circ}{ }_{2} .-\mathrm{G}^{\circ}$, and $-\mathrm{G}^{\circ}{ }_{4}$. This version of the model predicts the sense and relative timing of the inclination and intensity records in both the upper Olduvai and the lower Jaramillo transitions. The same version of the model produces synthetic records in agreement with those observed at the latitude of Hole 609B. Because complete intensity records were not obtained at Hole $609 \mathrm{~B}$, there is no control on the

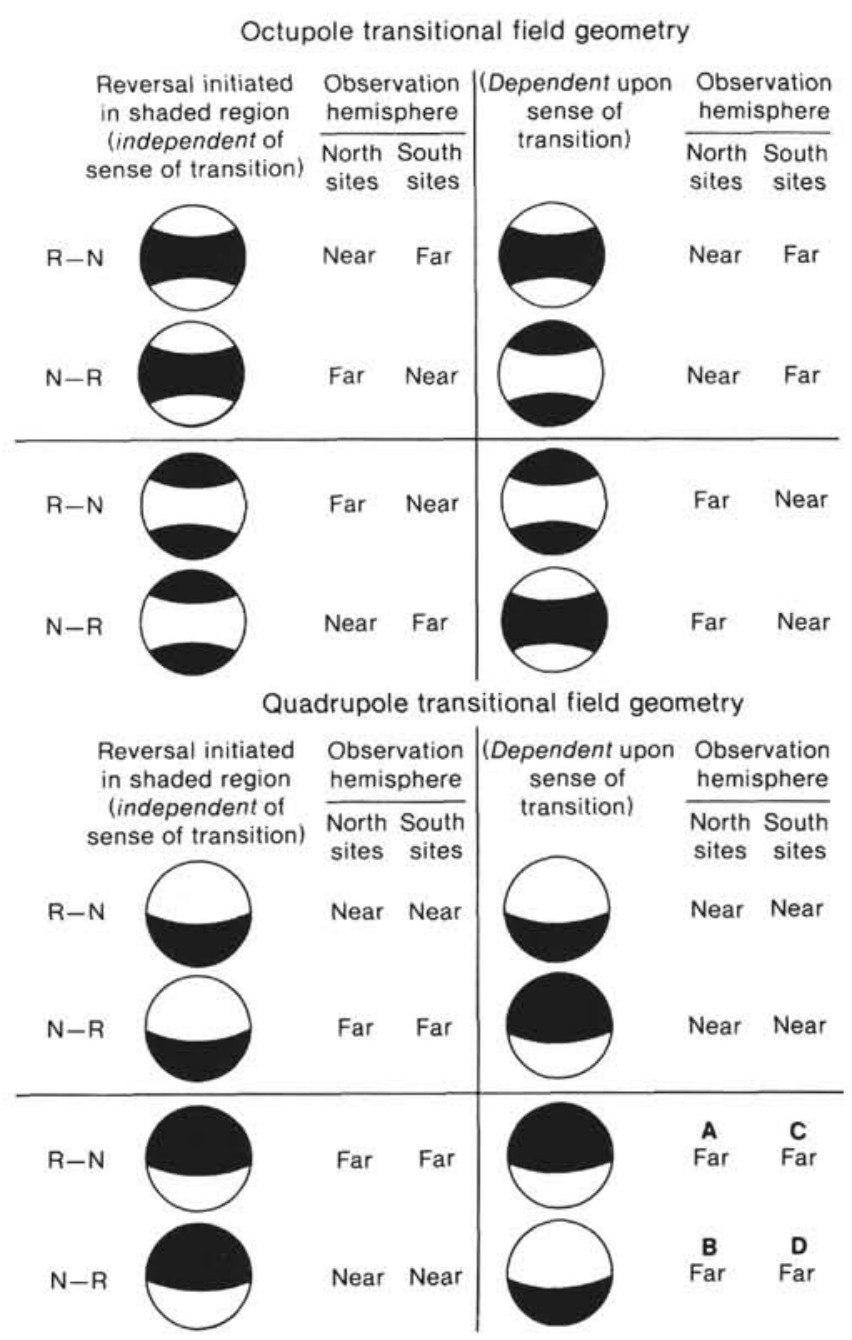

Figure 27. VGP paths predicted by octupole and quadrupole field geometries by Hoffman's flooding model (after Fuller et al., 1979). The observed VGP paths from Hole 609B (A and B) and from RC14-14 (C and D) from the lower Jaramillo and upper Olduvai form a data set that fully constrains Hoffman's model as indicated. 
scaling of the synthetic records to the observed records, and a rigorous analysis of the fit cannot be undertaken. However, the relative sense and timing of the vertical directions with respect to horizontal directions in the Hole 609B data are well predicted by the synthetic records. The synthetic records produced by this version of the model for the latitude of Hole 609B are shown in Figure 28 together with records predicted using the version Williams and Fuller (1981) developed for the MatuyamaBrunhes transitional field. Comparison of these synthetic records with the lower Jaramillo and upper Olduvai records from Hole 609B, shown in Figures 19 and 23, respectively, indicates that a better fit to the observed records is obtained if a negative $\mathrm{G}^{\circ}{ }_{2}$ term is used in the modeling.

\section{CONCLUSIONS}

A detailed sampling method was employed to obtain paleomagnetic records across eleven polarity reversal
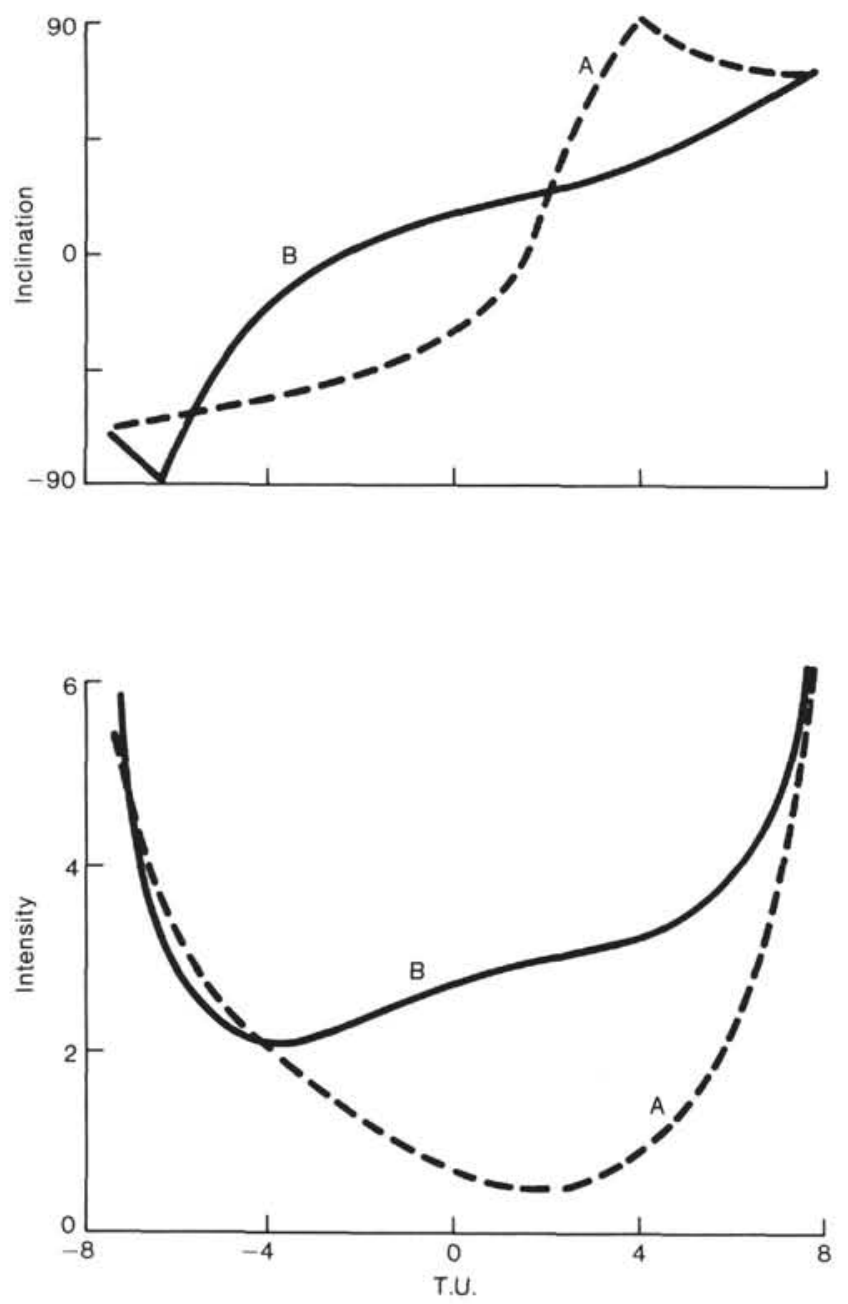

Figure 28. Synthetic inclination and intensity records across a reverse to normal transition at the site latitude of Hole 609B. $\mathrm{A}=$ the record predicted by the version of the model developed by Williams and Fuller (1981) with the energy partitioned with 20,30 , and $50 \%$ going to $+\mathrm{G}_{2}^{\circ},-\mathrm{G}_{3}^{\circ}$, and $+\mathrm{G}^{\circ}{ }_{4}$. $\mathrm{B}=$ is the record predicted using the version used to model the RC14-14 records (in this version the energy is partitioned with 20,30 , and $50 \%$ going to $-\mathrm{G}_{2}^{\circ}$, $-\mathrm{G}^{\circ}{ }_{3}$, and $\left.-\mathrm{G}^{\circ}{ }_{4}\right)$. T. $\mathrm{U}$. $=$ time units. boundaries in wet sediments cored with the hydraulic piston corer in the North Atlantic. Continuous polarity transitions were sampled by taking 0.5 -cm-thick slices from long sections that were measured using a cryogenic magnetometer. Of the five sites at which the transitions were sampled, only one, Hole 609B, produced results that meet the criteria required for interpreting the results as records of transitional field behavior. The results from Holes 606A, 607A, 610B, and 610C were characterized by intermediate directions that are products of multicomponent magnetizations; in some instances the full normal and reverse polarity directions are not antipodal. These observations place the recording fidelity of the sediments on this scale in question, although magnetostratigraphic results from these same holes (Clement and Robinson, this volume) suggest that over a larger scale these sediments are very good recorders of the geomagnetic field reversal history.

Three of the four records from Hole 609B contain internally consistent transition records that are interpreted as records of field behavior during the reversal. As such they provide constraints on transitional field models. The Matuyama-Brunhes transition exhibits a near-sided VGP path, consistent with Hoffman's observation (1977) of the near-sided nature of Northern Hemisphere VGP paths from this reversal. Without Southern Hemisphere records, however, his zonal flooding model cannot distinguish between the possible zonal field geometries. The lower Jaramillo and upper Olduvai transitions therefore are important, because they allow for the first time the comparison of records of the same transition from both hemispheres. The combined set of transitions from Core RC14-14 and Hole 609B also provide records of both N to $\mathrm{R}$ and $\mathrm{R}$ to $\mathrm{N}$ reversals, allowing the examination of the possible dependence of the transitional field geometry on the sense of the reversal.

The declination records of these four sites indicate that the transition fields were not purely axisymmetric. The success in modeling the inclination and intensity records using a version of the Williams and Fuller type model, however, indicates that large-scale zonal symmetries are present in these transitional fields. Hoffman's zonal flooding model is fully constrained by this set of reversals, which indicate that the nature of the reversal is dependent upon the sense of the reversal within this model's framework; in this case the transitional fields were dominated by a quadrupolar geometry.

\section{ACKNOWLEDGMENTS}

We thank Ken Hoffman, Neil Opdyke, and Lisa Tauxe for reviewing this chapter and making helpful suggestions. Doris Lafferty assisted with the laboratory measurements. A special thanks is extended to Ellen Thomas, Bill Ruddiman, and Rob Kidd whose assistance aided in allowing these samples to be taken. This work was supported by NSF contract OCE 8300356 and is Lamont-Doherty Geological Observatory Contribution Number 3931.

\section{REFERENCES}

Bannerjee, S., King, J., and Mervin, J., 1981. A rapid method for magnetic granulometry with application to environmental studies. Geophys. Res. Lett., 8:333-336.

Clement, B. M., and Kent, D. V., 1984a. A detailed record of the lower Jaramillo polarity transition from a southern hemisphere deep-sea sediment core. J. Geophys. Res., 89:1049-1058. 
, 1984b. Latitudinal dependency of geomagnetic polarity transition durations. Nature, 310:488-491.

, 1985. A comparison of two sequential geomagnetic polarity transitions (upper Olduvai and lower Jaramillo) from the Southern Hemisphere. Phys. Earth Planet. Interiors, 39:301-313.

Clement, B. M., Kent, D. V., and Opdyke, N. D., 1982. Brunhes-Matuyama polarity transition in three deep-sea cores. Phil. Trans. $R$. Soc. London, A306:113-119.

Fisher, F. R. S., 1953. Dispersion on a sphere. Proc. R. Soc. London Ser. $A, 217: 295-305$.

Fuller, M., Williams, I., and Hoffman, K. A., 1979. Paleomagnetic records of geomagnetic field reversals and the morphology of the transitional fields. Rev. Geophys. Space Phys., 17:179-203.

Gurarii, G. Z., 1981. The Matuyama-Jaramillo geomagnetic inversion in western Turkmenia. Izvestiya, Earth Phys., 17:212-218.

Hillhouse, J., and Cox, A., 1976. Matuyama-Brunhes polarity transition. Earth Planet. Sci. Lett., 29:51-64.

Hoffman, K. A., 1977. Polarity transition records and the geomagnetic dynamo. Science, 196:1329.

,1979. Behavior of the geodynamic during reversal: a phenomenological model. Earth Planet. Sci. Lett., 44:7-17.

Hoffman, K. A., and Fuller, M., 1978. Transitional field configurations and geomagnetic reversals. Nature, 273:715-718.

Irving, E., and Major, A., 1964. Post-depositional detrital remanent magnetization in a synthetic sediment. Sedimentology, 3:135-143.

Kent, D. V., 1973. Post depositional remanent magnetization in deepsea sediment. Nature, 246:32-34.

Kent, D. V., and Spariosu, D. J., 1982. Magnetostratigraphy of Caribbean Site 502 hydraulic piston cores. In Prell, W. L., Gardner, J. V., et al., Init. Repts. DSDP, 68: Washington (U.S. Govt. Printing Office), 419-433.
King, J., Bannerjee, S. K., Marvin, J., and Ozdemir, O., 1982. A comparison of different magnetic methods for determining the relative grain size of magnetite in natural materials: some results from lake sediments. Earth Planet. Sci. Lett., 59:404-419.

Niitsuma, N., 1971. Detailed study of the sediments recording the Matuyama-Brunhes geomagnetic reversal. Tohoku Univ. Sci. Rept. 2nd Ser. (Geology), 43:1-39.

Tauxe, L., LaBrecque, J. L., Dodson, R., and Fuller, M., 1983. "U” Channels - a new technique for paleomagnetic analysis of hydraulic piston cores. EOS, 64:219 (Abstract)

Tauxe, L., Opdyke, N. D., Pasini, G., and Elmi, C., 1983. Age of the Plio-Pleistocene boundary in the Vrica section, southern Italy. $\mathrm{Na}$ ture, 304:125-129.

Tauxe, L., Tucker, P., Peterson, N., and LaBrecque, J. L., 1983. The magnetostratigraphy of Leg 73 sediments. Paleogeogr., Paleoclimatol., Paleoecol., 42:65-90.

Verosub, K. L., and Bannerjee, S. K., 1977. Geomagnetic excursions and their paleomagnetic record. Rev. Geophys. Space Phys., 15: $145-155$.

Williams, I., and Fuller, M., 1981. Zonal harmonic models of reversal transition records. J. Geophys. Res., 86:11,657-11,665.

Zijderveld, J. D. A., 1967. A. C. demagnetization of rocks: analysis of results. In Collison, D. W., Creer, K. M., and Runcorn, S. K. (Eds.), Methods in Paleomagnetism: New York (Elsevier), pp. 254286.

Date of Initial Receipt: 12 April 1985

Date of Acceptance: 14 January 1986 